\title{
Aproximación sociológica al terrorismo global ${ }^{1}$ A sociological approach to global terrorism
}

\author{
Diego Ortega Fernández \\ UNED \\ dortega57@alumno.uned.es
}

\begin{abstract}
Resumen: Con este trabajo realizamos, en primer lugar, un acercamiento polemológico al terrorismo. Para ello analizamos las relaciones entre terrorismo y una serie de factores socioestructurales obtenidos de los índices publicados por distintas organizaciones internacionales: desarrollo humano (DIH-D), pobreza, corrupción, inmigración, etc. Complementariamente, realizamos un perfil descriptivo de una muestra de 667 terroristas cuyos datos han sido obtenidos de los medios de comunicación y bibliografía (fuentes abiertas). El objeto del trabajo es confirmar si, con la utilización de este tipo de fuentes sobre un tema tan complejo como el terrorismo, se pueden obtener resultados coincidentes con estudios realizados sobre el mismo por otros investigadores. Como resultado, nuestras conclusiones han sido coincidentes con estos estudios. Por lo tanto, podemos aportar a la comunidad que se pueden realizar trabajos de investigación sobre temas en los que la disponibilidad de información no es abierta, o es de difícil acceso, apoyándose en la información que circula por internet debidamente contrastada. Entre los resultados obtenidos destacamos que el terrorismo es independiente de la pobreza, pero está relacionado con sociedades de menor desarrollo y con alta percepción de corrupción y de injusticia.
\end{abstract}

Palabras clave: terrorismo, guerra, violencia estructural, suicidio.

\begin{abstract}
In this work we approach terrorism from the perspective of war studies. To do this, we analyze the relationships between terrorism and a series of socio-structural factors. These factors consist of indices obtained from different international organizations, such as human development (IHL-D), poverty, corruption, immigration, etc. In addition, we developed a descriptive terrorist profile
\end{abstract}

${ }^{1}$ El presente artículo parte de la tesis doctoral que el autor ha defendido en la UNED con el título «Factores culturales y estructurales de la violencia terrorista. Su incidencia en el campo islámico», calificada cum laude. 
using a sample of 667 terrorists. These open-source data have been obtained from the media and bibliography. Our main aim is to confirm that it is possible to replicate a terrorist profile, similar to that developed by other researchers using restricted-access data but using exclusively open-source data. Our results indicate that open-source based terrorist profiling is possible and leads to similar results than those based on restricted-access data. In the context of sociology, research on sensitive topics such as terrorism is mostly limited to restricted information sources that are difficult to access. We show that it is possible to carry out sociological research on information circulating the internet given that it has been duly verified. We believe this will facilitate future research about terrorism and similar topics. Finally, in line with previous restricted-data based profiles, our open-access based profile highlights that terrorism is independent of poverty but it is related to less developed societies with a high perception of corruption and injustice.

Key-words: terrorism, war, structural violence, suicide 


\section{INTRODUCCIÓN}

La utilización del terror como forma de ejercer la violencia ha estado presente a lo largo del proceso de civilización de la humanidad. Hasta la promulgación del Derecho Internacional Humanitario (DIH), también conocido como Derecho de la Guerra, el terror formaba parte de las estrategias bélicas. Polibio describe la crueldad que desplegó Escipión el Africano en la toma de Cartago Nova (209 a. C.) como una costumbre habitual del ejército romano para sembrar el terror (Keegan, 2014). Esto no quiere decir que, como resultado de la promulgación del DIH, el hecho de aterrorizar haya desaparecido en los conflictos actuales, pero al menos hay una intención y unos recursos legales para perseguir y condenar tales actos.

Por su parte, el terrorismo considerado como un hecho o fenómeno de la violencia política y social con identidad propia tiene su origen en la Revolución Francesa de 1789 y está asociado al miedo, el gran miedo de la aristocracia y, posteriormente, también de la burguesía. Todo ello ante los derroteros que tomaba la revolución y que convirtió a muchos ciudadanos en sospechosos de contrarrevolucionarios y, por tanto, susceptibles de ser reprimidos (Godechot, 1981).

En cuanto a la definición sociopolítica del terrorismo, la cuestión es bastante difusa. No hay un acuerdo generalizado que vaya más allá del hecho de producir daños a personas o cosas con la finalidad de forzar un cambio político. En la historia política encontramos personalidades que hoy tienen una alta consideración social y, en su día, fueron catalogados como terroristas, como fue el caso de Nelson Mandela (Giddens y Sutton, 2014).

En el presente trabajo optamos por la definición de terrorismo adoptada por Naciones Unidas (NN. UU.) y elaborada por Alex P. Schmid y A. J. Jongman en 1988. Estos autores definen el terrorismo partiendo de una serie de factores que podríamos resumir en: el terrorismo es una forma de violencia política que se basa en generar un miedo intenso en la comunidad para conseguir unos objetivos racionales y amparado en la manipulación ideológica²; ejerce efectos psicológicos importantes en la población que lo sufre; y su fuerza no radica en el potencial destructivo, sino en las significaciones que las personas dan a esta forma de violencia. El impacto psicológico que tiene sobre las personas es tan letal como las bombas al provocar en ellas sentimientos de indefensión (Gonzalez-Calleja, 2016). Y propone Schmid que, desde el punto de vista legal, los actos terroristas en tiempo de paz son crímenes de guerra ${ }^{3}$.

${ }^{2}$ https://web.archive.org/web/20070527145632/http://www.unodc.org/unodc/terrorism_definitions. html

${ }^{3}$ https://web.archive.org/web/20070527145632/http://www.unodc.org/unode/terrorism_definitions. html 
Como se desprende de la definición, el terrorismo es un fenómeno complejo que se manifiesta en el contexto de lo que Norbert Elias denomina «la sociedad de los individuos» (Elias, 1990) y que es el resultado de la interacción entre lo psicológico, lo político y por tanto social, y lo histórico.

Es evidente que, en un espacio como este, y ni siquiera en otro más amplio, resultaría imposible abarcar el fenómeno terrorista en toda su amplitud. Es por ello que el estudio del terrorismo ha de ser descompuesto y tratado en cada una de sus componentes por las ciencias que expliquen mejor cada una de estas. De la integración de los conocimientos derivados de cada una se podrá tener un conocimiento más objetivo del fenómeno.

Desde el punto de vista de la sociología política, dado que el terrorismo es una forma de violencia que pretende cambiar o forzar el cambio en un determinado orden social, será objeto de estudio sociológico el modelo o modelos de orden social de las sociedades en que tiene presencia.

La sociología ha abordado los estudios sobre terrorismo basándose en dos criterios fundamentales pero no excluyentes: aquellos que siguen una línea histórico-temporal y los asociados a las diferentes escuelas teóricas de la sociología: funcionalista, estructuralista, de las decisiones racionales y cultural antropológico.

Los primeros dividen los estudios sobre el terrorismo en vieja y nueva escuela. La primera está vinculada a trabajos que relacionan el terrorismo con movimientos ideológicos como el anarquismo, el marxismo, la extrema derecha, etc.; también a movimientos independentistas derivados del colonialismo; movimientos secesionistas de carácter político, étnico, religioso, cultural, etc., o a una combinación de varios de ellos. Suelen hacer referencia a un modelo de terrorismo localizado.

La nueva escuela concibe las investigaciones sobre el terrorismo enmarcándolas en un sistema global asociándolo al avance de las nuevas tecnologías de la información. Este modelo está, a su vez, en estrecha relación con el conflicto palestino-israelí y el resurgimiento del fundamentalismo islámico. Entre otras cosas se caracteriza por mantener estrechas relaciones con la delincuencia: tráfico de drogas, personas, armas, etc.

Desde una perspectiva teórica, los estudios sobre terrorismo han seguido las líneas de las diferentes escuelas sociológicas, aunque rara vez de forma exclusiva, pues el terrorismo, como la mayoría de los hechos sociales, es un fenómeno que presenta un grado de complejidad igual al de la estructura de la sociedad en que se manifiesta, como propone la profesora Melanie Mitchell (Colom y Ballester, 2020).

Desde el punto de vista del funcionalismo, los estudios sobre el terrorismo se enfocan como un tipo de respuesta a una serie de imperativos funcionales o necesidades demandados por la sociedad, grupo o colectivo, que permiten su adaptación al medio y 
el funcionamiento del sistema social. Imperativos que pueden responder a necesidades materiales o ideológicas.

El enfoque estructuralista, como su nombre indica, estudia el fenómeno terrorista desde la perspectiva de la estructura social y las desigualdades que comporta. Se aborda el análisis a partir de los desequilibrios estructurales en una sociedad, es decir, todo aquello que impide el desarrollo de las potencialidades de las personas y que genera violencia estructural (Galtung, 1969). Esta perspectiva de estudio resulta especialmente interesante por cuanto las diferencias sociales y las injusticias que conlleva suelen ser muy aceptadas como legitimadoras de la violencia terrorista.

Los defensores de la teoría de las decisiones racionales, cuya representante más destacada es Martha Crenshaw, analizan el terrorismo como una forma de juego político cuyos jugadores siguen el principio de maximizar beneficios y minimizar riesgos (Dowse y Hughes, 1982). Crenshaw se basa en un comportamiento eminentemente racional. Sus objetivos no suelen ser materiales, sino simbólicos. El objetivo no es en vencer al Estado, sino desmoralizar y amedrentar a la población aumentando su nivel de ansiedad por indefensión y, por tanto, su descontento. Esta forma de actuación fue evidenciada y promovida por Franz Fanon en la guerra de independencia de Argel (Fanon, 2013).

El enfoque antropológico cultural parte del principio de que toda acción humana tiene una razón explicable en el seno de una cultura, religión o cosmogonía. Por lo tanto, para comprender a los terroristas, hay que estudiarlos en el contexto sociocultural en que se han socializado. Talal Asad indica que el terrorismo, especialmente el yihadista de carácter suicida, ha de ser analizado desde la perspectiva de los terroristas y las razones culturales y socioeconómicas que les impulsan (Asad, 2008).

Para este trabajo adoptamos un enfoque holístico en la aproximación sociológica al terrorismo. Centramos el interés en el de naturaleza global, dado que los índices de terrorismo con los que trabajamos están referidos al año 2018 y, como ya sabemos, a partir de los acontecimientos del 11 de septiembre de 2001, el terrorismo relacionado con la cultura islámica abarca el escenario mundial. Todo ello sin desestimar el que actualmente tiene presencia en ámbito local, especialmente en los conflictos independentistas territoriales en el Sudeste Asiático: Cachemira (India), Sri Lanka (tamiles), Birmania (rohingyas), etc.; aunque en algunos de ellos subyace el conflicto étnico-religioso donde el islam está presente.

Atendemos a dos aspectos: en primer lugar, la relación entre el terrorismo y factores socioestructurales (desarrollo humano, la pobreza, la injusticia y la corrupción); en segundo lugar, analizamos algunos aspectos que nos pueden ayudar a entender quiénes son los terroristas y si hay diferencias entre ellos según su ideología. 


\section{OBJETIVO, HIPÓTESIS, FUENTES Y METODOLOGÍA}

Con el presente trabajo nos proponemos reafirmar las conclusiones obtenidas por otros investigadores según las cuales la violencia terrorista utiliza las ideologías de una forma interesada para alcanzar unos fines políticos que favorecen, fundamentalmente, al grupo o movimiento que los promulga. En definitiva, que los principios sobre los que se pretende legitimar el terrorismo se basan en una distorsión de la realidad social (De la Corte, 2007).

Como ya hemos dicho y, en base a la limitación de este trabajo, nos centramos en dos perspectivas del fenómeno, concretamente en responder a las preguntas: ¿Qué influye más sobre el terrorismo, la pobreza o la injusticia asociada a un bajo desarrollo humano y una alta tasa de percepción de la corrupción? ¿Hay relación entre el hecho de ser terrorista y algunos trastornos de la personalidad o de la conducta?

Partimos de las hipótesis de que no hay relación entre pobreza y terrorismo, por lo que, en nuestra opinión, el terrorismo no se puede justificar como la forma que tienen los pobres de hacer la guerra. En segundo lugar, que los terroristas no son personas pobres, y que tampoco son individuos que mayoritariamente estén sumidos en la marginalidad social o sean víctimas de desórdenes de la personalidad.

Utilizamos básicamente una metodología estadística descriptiva. Las técnicas que empleamos con mayor frecuencia son: las correlaciones de Pearson para variables cuantitativas y las tablas de contingencia para variables cualitativas. En estas últimas, los análisis de asociación los realizamos mediante la prueba de X2 (chi-cuadrado). Teniendo presente que, con estas técnicas solo podemos apreciar el grado o fuerza de las correlaciones o asociaciones entre las variables, pero no establecer relaciones de dependencia causa-efecto entre ellas. El hecho de que dos variables estén correlacionadas no significa que los cambios en una provoquen cambios en la otra, pues puede haber otras variables intervinientes. Nos hemos servido del paquete estadístico IBM-SPSS puesto a disposición de los alumnos de la UNED.

Para este trabajo utilizamos dos tipos de variables: poblacionales y muestrales. Las primeras, relativas a todos los países reconocidos por Naciones Unidas, a excepción de islas y pequeños territorios soberanos; sí hemos considerado los territorios palestinos por su importancia para el tema central de este trabajo. Las fuentes principales de datos utilizadas se citan en el aparatado de bibliografía.

Con respecto a la muestra de 667 terroristas, esta ha sido elaborada por el autor de este trabajo recogiendo datos de los terroristas que han tenido presencia en los medios de comunicación y bibliografía sobre el tema. Como ya hemos comentado, nuestras conclusiones están orientadas al terrorismo global; de hecho, 527 individuos de la muestra son terroristas relacionados de una u otra forma con la cultura islámica. El resto de 
los casos (140) se distribuye entre diferentes ideologías (anarquista, extremistas de izquierda y derecha, neonazis, antiabortistas, nacionalistas, etc.). Igualmente, las fuentes de datos se citan en la bibliografía.

\section{TERRORISMO Y DESIGUALDAD: DESARROLLO HUMANO, POBREZA, INJUSTICIA Y CORRUPCIÓN}

En el presente apartado analizamos las relaciones entre terrorismo e indicadores socioestructurales como la desigualdad social. Estos vínculos nos parecen relevantes porque sobre ellos se construyen discursos que tienen como finalidad legitimar el hecho terrorista. Las ideologías que se apoyan en el terrorismo presentan esta forma de acción política como resultado de la violencia cultural y estructural que el poder o una parte de la sociedad ejerce sobre la otra (De la Corte 2007).

Está sobradamente estudiado que hay situaciones y contextos relacionados con la marginalidad y la desigualdad en los que las conductas agresivas y la violencia tienen una especial presencia. Ahora bien, la desigualdad es un concepto complejo, cuyas variedades pueden actuar de formas muy diferentes a la hora de que las personas perciban sus diferencias como generadoras de violencia (género, sexualidad, etnia, raza, disponibilidad económica, bienestar, etc.); ello dependerá del contexto en que analizamos el binomio desigualdad-violencia.

J. Galtung formuló la teoría del triángulo de la violencia. En ella considera que la violencia presente, la que se ve, es el resultado de otras dos que no son tan visibles: la violencia derivada de la estructura social, violencia estructural; y, la asociada al modelo socio cultural, violencia cultural. En general, las violencias estructural y cultural estarán vigentes en tanto que las instituciones sociales, las estructuras de poder y los sistemas culturales creen barreras para algunas personas o colectivos (pobres, mujeres, minorías étnicas, sexuales y religiosas, emigrantes y refugiados, etc.) a la hora de ejercer sus derechos o desarrollar sus proyectos de vida. Por lo tanto, este tipo de violencia acompaña siempre a la humanidad. Cuanto mejor conozcamos sus causas y efectos, mayores probabilidades habrá de componer órdenes sociedades con bajos niveles de violencia estructural y, por tanto, con su correspondiente incidencia sobre la violencia directa (Galtung, 1969).

En base a lo anterior, y como ya hemos comentado, nuestra hipótesis es que el fenómeno terrorista es independiente de factores estructurales relacionados con la disponibilidad monetaria, y no con factores derivados de la percepción de injusticia. Como expone el profesor De la Corte, citando a Wolfesohn, «la mayoría de las personas pobres están más interesadas en su día a día que en unirse a un grupo terrorista» (De la Corte, 2007: 
2). Sin embargo, cuando se perciben situaciones injustas, se dispara la emoción de la ira, y nos hacemos más propensos al uso de la violencia para equilibrar la situación. Si bien esto no legitima ni justifica la violencia, en nuestro caso el terrorismo, solo nos ayuda a entender, aunque de forma muy imperfecta, un aspecto de la conducta humana.

\section{Terrorismo, pobreza, desarrollo humano y corrupción}

Como venimos argumentando, nos interesa analizar estas interrelaciones porque, como hemos comentado, nos parecen sociológicamente relevantes, ya que sobre ellas se construyen en gran parte los discursos justificativos que pretenden dar legitimidad a las acciones terroristas. La justificación de las desigualdades es una cuestión fácilmente manipulable y de un alto contenido ideológico y su aceptación o no por quienes las sufren son la base de un determinado orden social. Dado que el terrorismo pretende subvertir un orden para generar otro, es lógico pensar que la desigualdad estará en la base ideológica de su discurso como instrumento de movilización.

Hemos correlacionado las variables Índice de Terrorismo Global (ITG) para 2018 y la Tasa de Incidencia de la Pobreza ${ }^{4}$. Observamos que no hay correlación entre ambas variables, son independientes (tabla 1). El hecho de ser pobre, miserablemente pobre, no está vinculado con el fenómeno terrorista. Las personas que viven en situaciones de pobreza extrema son a su vez las que ocupan el estrato más bajo de la estructura de cualquier sociedad, independientemente del nivel de desarrollo de aquella. Esta situación vital lleva a los individuos a dedicar sus vidas y tiempo a la satisfacción de las necesidades más básicas para la supervivencia. En conclusión, encontramos que los países en los que la proporción de pobres es mayor presentan menores índices de terrorismo.

TABLA 1

\begin{tabular}{ccc}
\hline $\begin{array}{c}\text { Correlación entre Índice de Terrorismo Global e } \\
\text { Incidencia Pobreza sobre } \mathbf{1 , 9 0} \$ \text { día }\end{array}$ & \multicolumn{1}{c}{$\begin{array}{c}\text { Índice de Terrorismo } \\
\text { Global (ITG) }\end{array}$} \\
$\begin{array}{c}\text { Incidencia Pobreza sobre } \\
1,90 \text { \$ día }\end{array}$ & Correlación de Pearson & 0,110 \\
\cline { 2 - 3 } & $\mathrm{Sig.} \mathrm{(bilateral)}$ & $0,136>0,05$ \\
\hline
\end{tabular}

Fuente: Banco Mundial y Global Terrorism Database. Elaboración propia.

${ }^{4}$ La Tasa de Incidencia de Pobreza se define por el Banco Mundial como el porcentaje de población que vive con, o por debajo de, $1,90 \$$ por día. 
Ahora bien, si en lugar de pobreza extrema hablamos de desarrollo, como en su día planteó el economista Amartya Sen, o de pobreza multidimensional ${ }^{5}$, sí que encontramos correlación (Tabla 2). La explicación a esta aparente paradoja la podemos encontrar en que el Índice de Desarrollo Humano corregido por la Desigualdad (IDH-D) es un índice más robusto, explica muchas más cosas que el simple hecho de la pobreza económica. En él intervienen factores indicativos de la implementación de los Derechos Humanos y de la calidad de vida de una sociedad, así como las desigualdades presentes en la misma.

TABLA 2

\begin{tabular}{lc}
\hline \multicolumn{1}{c}{ Correlaciones IDH-D y variables indicativas de violencia } & IDH-D \\
\hline Índice de Terrorismo Global (ITG) $\mathbf{2 0 1 8}$ & $\mathbf{- 0 , 2 0 9 *}$ \\
\hline Aplicación Arbitraria del Estado de Derecho & $-0,588^{* *}$ \\
\hline ** La correlación es significativa en el nivel 0,01 (bilateral). & \\
* La correlación es significativa en el nivel 0,05 (bilateral). & \\
Fuentes: ITG, UNDOC, Walk Free Fundation. Elaboración propia. &
\end{tabular}

Aunque como ya hemos comentado, en las correlaciones no podemos discriminar entre la variable causa y la variable efecto, de la tabla dos se desprende que a medida que disminuye el IDH-D, aumenta el ITG, y lo mismo ocurre con la variable Aplicación Arbitraria del Estado de Derecho, que es una componente del Índice de Estado Fallido (IEF).

En base a los datos del Banco Mundial, el PIB per cápita (PPA) entre 1990 y 2019 mantiene una tendencia ascendente para la media mundial. No obstante, la distribución de la riqueza no es homogénea y presenta grandes desequilibrios entre unas sociedades y otras, como podemos ver en la Gráfica 1. Mientras que en América del Norte y la Unión Europea el PPA crece muy por encima de la media mundial, en Oriente Medio, Norte de África y América Latina presenta un descenso a partir de 2015; África Subsahariana se encuentra muy por debajo de la media mundial. Es en estas zonas donde se concentra el terrorismo actual. A esto queda añadir los efectos que tendrá la pandemia de COVID-19 sobre estos y otros territorios. Las expectativas del Fondo Monetario Internacional (FMI) son poco alentadoras: «La historia está repleta de ejemplos de brotes de enfermedades que proyectan largas sombras de repercusiones sociales: dar forma a la política, subvertir el orden social y algunos, en última instancia, causar disturbios sociales» (Barrett y Cheny, 2021).

${ }^{5}$ Global Multidimensional Poverty Index 2017. Oxford Poverty and Human Development Initiative. Oxford University, www.opi.org.uk 


\section{GRÁFICA 1}

PIB per cápita PPA (\$ a parcios internacionales actuales)

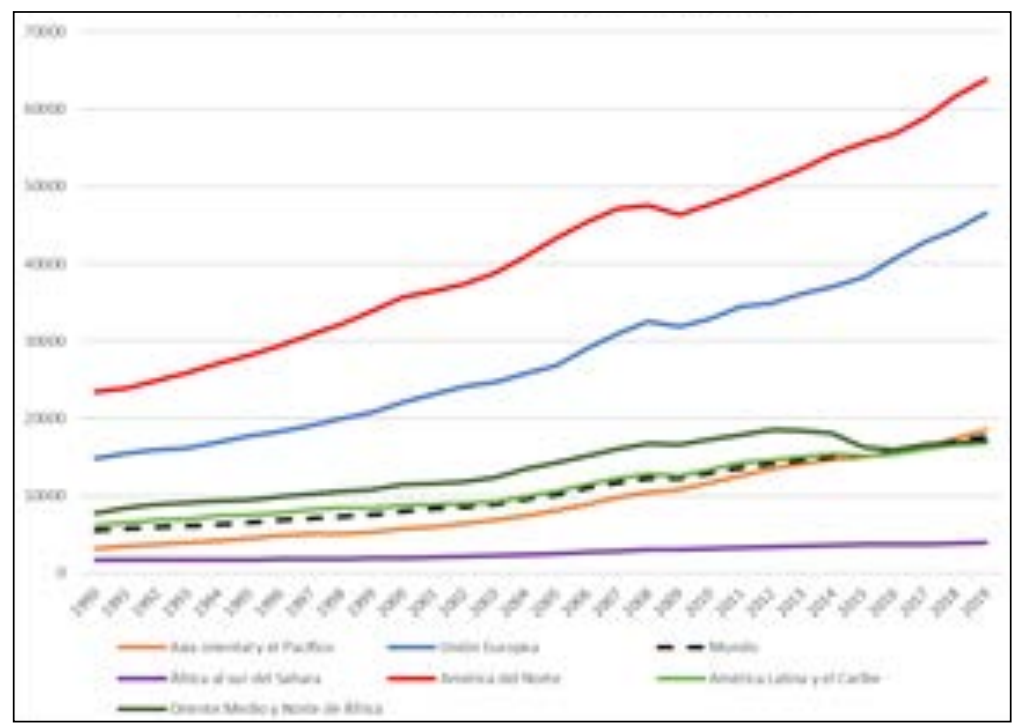

Fuente Banco Mundial. Elaboración propia.

Como vemos en la Tabla 3, hay correlación, aunque débil, entre el ITG y el PPA (PIB p.c.). El ITG aumenta cuando disminuye la capacidad adquisitiva de las personas de un país; a menos ingresos más terrorismo. A su vez, el PPA está correlacionado con la desigualdad en los ingresos; Índice de Gini (IG) ${ }^{6}$ (Tabla 4). Su correlación negativa nos indica que, en los países de ingresos más altos, las desigualdades económicas son menores que en los países donde los ingresos son más bajos. En estas sociedades, las diferencias económicas entre las personas son muy altas; unos pocos tienen mucho y muchos tienen muy poco (principio de Pareto).

TABLA 3

\begin{tabular}{llc}
\hline & & PIB p.c. \\
\hline \multirow{2}{*}{ ITG } & Correlación de Pearson & $\mathbf{- 0 , 1 5 5 *}$ \\
\cline { 2 - 3 } & Sig. (bilateral) & $0,035>0,05$ \\
\cline { 2 - 3 } & $\mathrm{N}$ & 186 \\
\hline
\end{tabular}

Fuente: Global Terrorism Index 2018 y Banco Mundial. Elaboración propia.

${ }^{6}$ El Índice de Gini varía entre 0, total igualdad, y 1, total desigualdad. 
TABLA 4

\begin{tabular}{llc}
\hline & & Índice de Gini \\
\hline \multirow{2}{*}{ PIB p.c. } & Correlación de Pearson & $\mathbf{- 0 , 3 7 6 * *}^{* *}$ \\
\cline { 2 - 3 } & Sig. (bilateral) & $0,000<0.01$ \\
\cline { 2 - 3 } & $\mathrm{N}$ & 186 \\
\hline
\end{tabular}

Fuente: Global Terrorism Index 2018 y Banco Mundial. Elaboración propia.

TABLA 5

\begin{tabular}{llc}
\hline & & Índice de Gini \\
\hline \multirow{2}{*}{ ITG } & Correlación de Pearson & $-0,011$ \\
\cline { 2 - 3 } & Sig. (bilateral) & $0,880>0,05$ \\
\cline { 2 - 3 } & $\mathrm{N}$ & 186 \\
\hline
\end{tabular}

Fuente: Global Terrorism Index 2018 y Banco Mundial. Elaboración propia.

Ahora bien, como vemos en la Tabla 5, el ITG no está correlacionado con el IG, esta falta de correlación parece indicar que terrorismo y desigualdad económica son independientes. En conclusión, podemos afirmar que, pese a que la disponibilidad de dinero y las desigualdades en los ingresos son factores intervinientes en el Desarrollo Humano, su relación con la violencia terrorista es escasa. El terrorismo afecta poco a los países muy pobres, que es donde se manifiestan las mayores desigualdades, pero su presencia aumenta cuando disminuye el IDH-D. Es por ello que consideramos que esta variable es un mejor indicador de las condiciones de vida de una sociedad que la disponibilidad económica. En nuestra opinión, y en base a los resultados obtenidos, las personas no consideran una gran injusticia tener mucho o poco dinero, pero sí no poder disponer de una sanidad, educación, libertades políticas, igualdad de género, vivienda, condiciones de trabajo adecuadas, libertades sexuales, etc. La globalización pone en evidencia estos desajustes. Los más desfavorecidos pueden ver cómo se vive en otras sociedades y, en consecuencia, tomar conciencia de la situación en que viven, paso previo a la acción.

No obstante, esto no quiere decir que esta acción tenga que ser necesariamente violenta. El terrorismo, en su estructura y funcionamiento, es un fenómeno de carácter psicosocial, de grupos, la sociedad solo actúa como víctima y receptora de la violencia terrorista. Por otra parte, se ha estudiado abundantemente por la sociología política que la privación y la frustración no tienen por qué terminar en acción política. En unas ocasiones se transformarán en movimiento y en otras no (Rivera, 2018). Lo que sí es cierto es que las socie- 
dades con un IDH-D constituyen el monto prioritario de víctimas del terrorismo global. El $76 \%$ de fallecidos en atentados terroristas viven en países de bajo IDH-D (Gráfica 2).

En conclusión, no podemos afirmar con rotundidad que aumentando y equilibrando los niveles de desarrollo humano en todos los países del mundo la lacra del terrorismo desaparecería, pero sí podemos estimar, como propone Galtung, que la violencia estructural derivada de las desigualdades se reduciría y, es muy probable, que también algunas formas de violencia política como el terrorismo. Tampoco parece muy acorde con la realidad la división sociológica entre terrorismo localizado y terrorismo global. Pues como venimos exponiendo el terrorismo hoy está localizado en las sociedades de bajo desarrollo humano, que son las que soportan el mayor número de víctimas e incidentes. Luego, lo que en nuestra opinión es global no es la incidencia del terrorismo en sí, sino la amenaza o el miedo a sufrirlo. Esto traslada el problema a cómo las sociedades, en base a esta amenaza, desarrollan sus estrategias de seguridad y la influencia que estas tienen en la vida social como «El nuevo urbanismo militar» del que habla Stephen Graham (Giddens y Sutton, 2014).

\section{GRÁFICA 2}

Porcentaje de víctimas mortales en atentados terroristas entre 1970 y 2018 por nivel de Desarrollo Humano

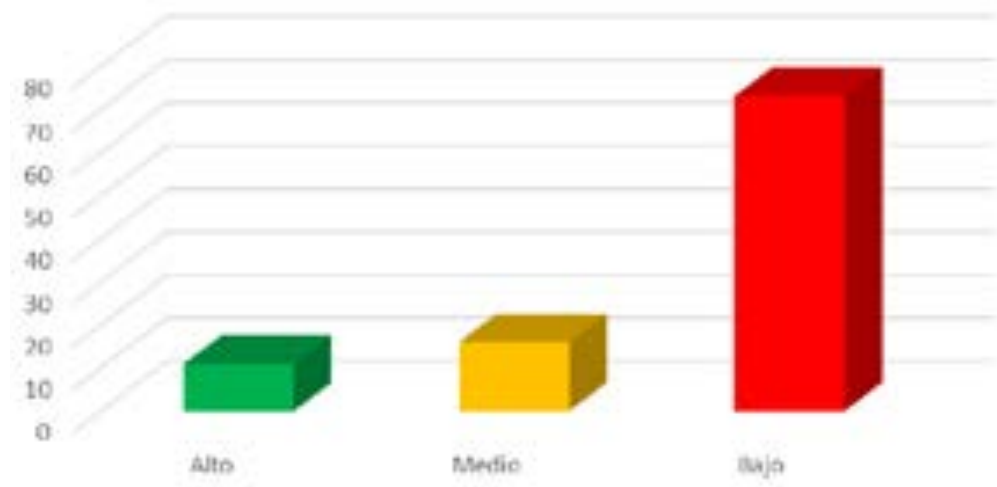

Fuente Global Terrorism Database y Banco Mundial. Elaboración propia.

\section{Terrorismo y corrupción}

La corrupción es una de las formas más notorias y presentes de violencia estructural. Es una práctica que se basa en el abuso de poder, se aprovecha de la buena voluntad de las personas y despierta en ellas las emociones de ira y rabia. El economista italiano 
Vito Tanzi define la corrupción como el incumplimiento intencionado del principio de imparcialidad con el propósito de derivar de tal tipo de comportamiento un beneficio personal o para personas relacionadas (Begovic, 2005). Por lo tanto, dice Begovic, para hablar de corrupción política se tienen que dar dos condiciones: intención y beneficio personal. Por otra parte, el concepto de corrupción política está sometido a las particularidades de valores que cada sociedad adopta como marco de referencia de su ética cultural.

Para el estudio de la corrupción trabajamos con datos obtenidos de la ONG Transparencia Internacional. Esta organización elabora un índice anual sobre la percepción de la corrupción, Índice de Percepción de la Corrupción (IPC), a través de las observaciones y opiniones de grupos de expertos (empresarios, juristas, analistas internacionales, etc.) y ciudadanos sobre cada país. El IPC tiene, por tanto, un carácter subjetivo. Este índice no expresa la corrupción en base a principios legislativos, sino a lo que las personas perciben de cuán corruptos son sus políticos e instituciones ${ }^{7}$. La elaboración del índice se basa en la observación de una serie de comportamientos corruptos y de mecanismos que tienen los Estados para prevenir la corrupción ${ }^{8}$.

En su relación con el terrorismo global, la primera cuestión que llama nuestra atención es la correlación entre el IPC y el ITG (Tabla 6), con pendiente negativa, cuando aumentan los valores de IPC (percepción de país poco corrupto) disminuyen los valores del ITG, o lo que es lo mismo, los países con mayores índices de terrorismo son los que se perciben con mayores niveles de corrupción. La ira derivada de la hipocresía e injusticia política parece ser más influyente sobre el terrorismo que factores relacionados con la pobreza. Vemos que la correlación entre terrorismo y corrupción es más fuerte que la presentada entre este y el IDH-D (Tabla 2) en valor absoluto (/0,293/ > /0,209/).

TABLA 6

\begin{tabular}{llc}
\hline & & ITG \\
\hline \multirow{2}{*}{ ITG } & Correlación de Pearson & $\mathbf{- 0 , 2 9 3 * *}$ \\
\cline { 2 - 3 } & Sig. (bilateral) & $0,000<0,05$ \\
\cline { 2 - 3 } & $\mathrm{N}$ & 186 \\
\hline
\end{tabular}

Fuente: Fuente: Transparencia Internacional y Global Terrorism Database. Elaboración propia.

${ }^{7}$ El IPC toma valores entre 100 (país nada corrupto) y 0 (país totalmente corrupto).

${ }^{8} \mathrm{https}: / /$ transparencia.org.es/wp-content/uploads/2018/02/metodologia_ipc-2017.pdf 
TABLA 7

Índice de percepción de la corrupción 2017

\begin{tabular}{ll}
\hline \multicolumn{1}{c}{ Región geográfica } & Media \\
\hline África Sahel & 42,0000 \\
\hline África Norte y Magreb & $\mathbf{3 4 , 1 6 6 7}$ \\
\hline África Subsahariana & $\mathbf{3 0 , 5 9 5 2}$ \\
\hline América del Norte & 67,7500 \\
\hline América Central y Caribe & 41,5000 \\
\hline América del Sur & 41,4545 \\
\hline Oriente Medio & 42,0667 \\
\hline Eurasia & $\mathbf{3 7 , 0 0 0 0}$ \\
\hline Asia Índico & $\mathbf{3 5 , 5 0 0 0}$ \\
\hline Asia Central & 40,8889 \\
\hline Asia Pacífico & 41,1667 \\
\hline Unión Europea & 63,6818 \\
\hline Europa no UE & 54,5789 \\
\hline Pacífico Sur & 52,7000 \\
\hline Total & 43,5968 \\
\hline
\end{tabular}

Fuente: Transparencia Internacional. Elaboración propia.

La región con una percepción de corrupción más alta es África Subsahariana, seguida del Norte de África y Magreb, Eurasia y Asia Índico; las de menor percepción, América del Norte y la Unión Europea (Tabla 7).

En relación con el terrorismo, el 8,8\% de los atentados, entre 1970 y 2018, se han cometido en países con una baja percepción de la corrupción (poco corruptos); el $38,4 \%$, en países con un nivel de corrupción de valor medio, entre los que se encuentra España; y el 52,8\%, en países con una corrupción política alta (Gráfica 3). 


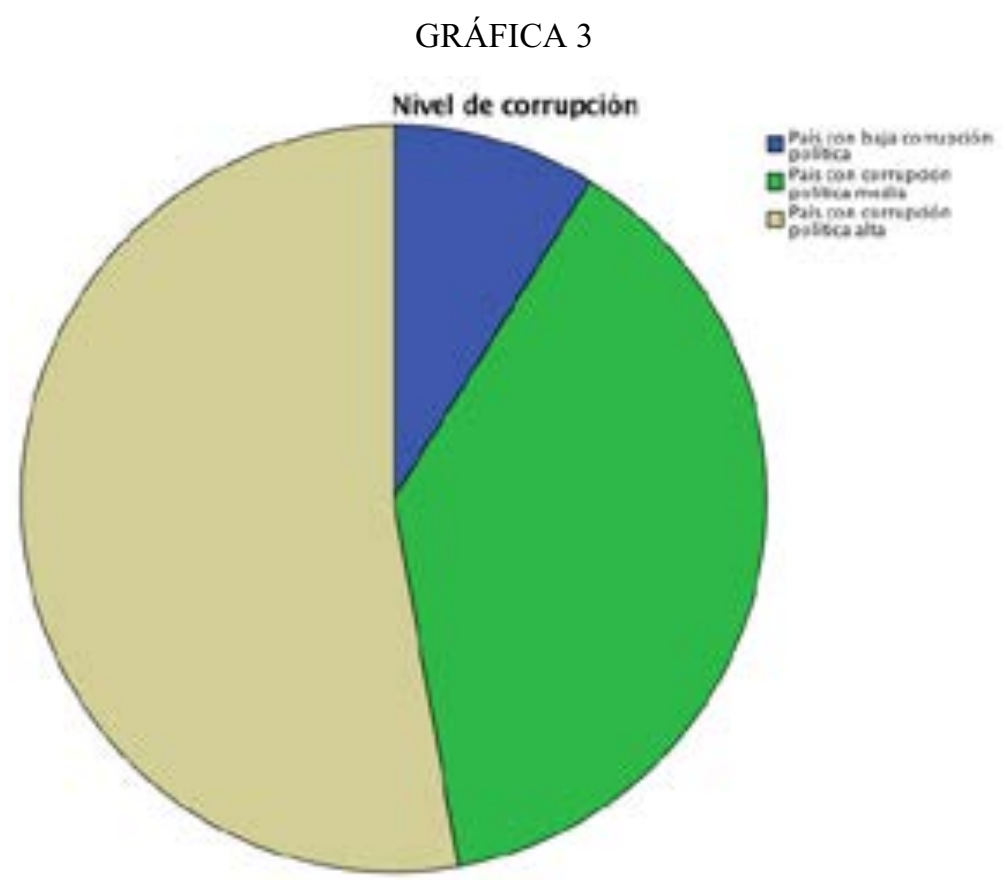

Fuente: Transparencia Internacional. Elaboración propia.

La Tabla 8 muestra la distribución de la percepción de corrupción en relación con la ideología de los grupos terroristas relacionados con incidentes terroristas en los diferentes países.

TABLA 8

Ideología del Grupo Terrorista * IPC del país donde actúan

\begin{tabular}{lcccc}
\hline & \multicolumn{3}{c}{ IPC } & \multirow{2}{*}{ Total } \\
\cline { 2 - 4 } & Bajo & Medio & Alto & \\
\hline Racismo y Xenofobia & $3,0 \%$ & $0,9 \%$ & $0,2 \%$ & $0,7 \%$ \\
\hline Fundamentalista Cristiano & $4,6 \%$ & $0,0 \%$ & $0,5 \%$ & $0,7 \%$ \\
\hline Extrema Derecha / Neofascista / Neonazi & $3,4 \%$ & $2,9 \%$ & $2,1 \%$ & $2,5 \%$ \\
\hline Delincuente / Criminal / Mafioso & $3,9 \%$ & $4,3 \%$ & $0,6 \%$ & $2,3 \%$ \\
\hline Derechos y Libertades & $7,2 \%$ & $1,4 \%$ & $0,1 \%$ & $1,2 \%$
\end{tabular}




\begin{tabular}{lcccc}
\hline & \multicolumn{3}{c}{ IPC } & Total \\
\cline { 2 - 4 } & Bajo & Medio & Alto & \\
\hline Terrorismo de Estado & $0,5 \%$ & $0,2 \%$ & $0,0 \%$ & $0,1 \%$ \\
\hline Fundamentalista Sionista & $1,0 \%$ & $0,1 \%$ & $0,1 \%$ & \\
\hline Fundamentalista Islámico & $4,9 \%$ & $8,2 \%$ & $\mathbf{7 3 , 7 \%}$ & $42,5 \%$ \\
\hline Apocalípticos y Mesiánicos & $0,1 \%$ & $0,0 \%$ & $0,0 \%$ & $0,0 \%$ \\
\hline Anarquista & $0,3 \%$ & $1,2 \%$ & $0,0 \%$ & $0,5 \%$ \\
\hline Derecha Democrática Liberal & $1,7 \%$ & $1,0 \%$ & $2,4 \%$ & $1,8 \%$ \\
\hline Sindical y Derechos Laborales & $0,5 \%$ & $0,1 \%$ & $0,0 \%$ & $0,1 \%$ \\
\hline Comunista Marxista o Maoísta & $13,1 \%$ & $\mathbf{4 9 , 0} \%$ & $15,7 \%$ & $28,3 \%$ \\
\hline Ecologistas y Medioambiente & $2,7 \%$ & $0,0 \%$ & $0,2 \%$ & \\
\hline Nacionalistas e Independentistas & $\mathbf{5 1 , 3 \%}$ & $17,6 \%$ & $3,1 \%$ & $12,9 \%$ \\
\hline Liberación de Palestina & $1,5 \%$ & $10,9 \%$ & $0,5 \%$ & $4,6 \%$ \\
\hline Étnico / Tribal & $0,1 \%$ & $0,1 \%$ & $0,3 \%$ & $0,2 \%$ \\
\hline Total & $100,0 \%$ & $100,0 \%$ & $100,0 \%$ & $100,0 \%$ \\
\hline Funn & $D \%$ & & \\
\hline
\end{tabular}

Fuente: Fuente: Transparencia Internacional y Global Terrorism Database. Elaboración propia.

Observamos que, en las sociedades donde la percepción de corrupción es baja, la ideología predominante de los grupos terroristas está vinculada con el nacionalismo independentista. En las de nivel medio actúan en mayor proporción grupos de ideología marxista; en ambos casos responden al modelo de terrorismo localizado. En los Estados en los que la percepción de la corrupción es alta, la ideología terrorista más frecuente es la vinculada con la cultura islámica, terrorismo palestino e islamista, fundamentalmente. Si a esto añadimos que el IPC está fuertemente correlacionado con el IDH-D $(\mathrm{r}=0,713 ; \mathrm{s}=0<0,5)$ (Gráfica 4), podemos concluir que las sociedades más corruptas son las menos desarrolladas y las que manifiestan un mayor ITG. Lo que parece fundamentar la idea de que el terrorismo está más relacionado con los sentimientos de injusticia que con los de necesidades estrictamente materiales. 


\section{GRÁFICA 4}

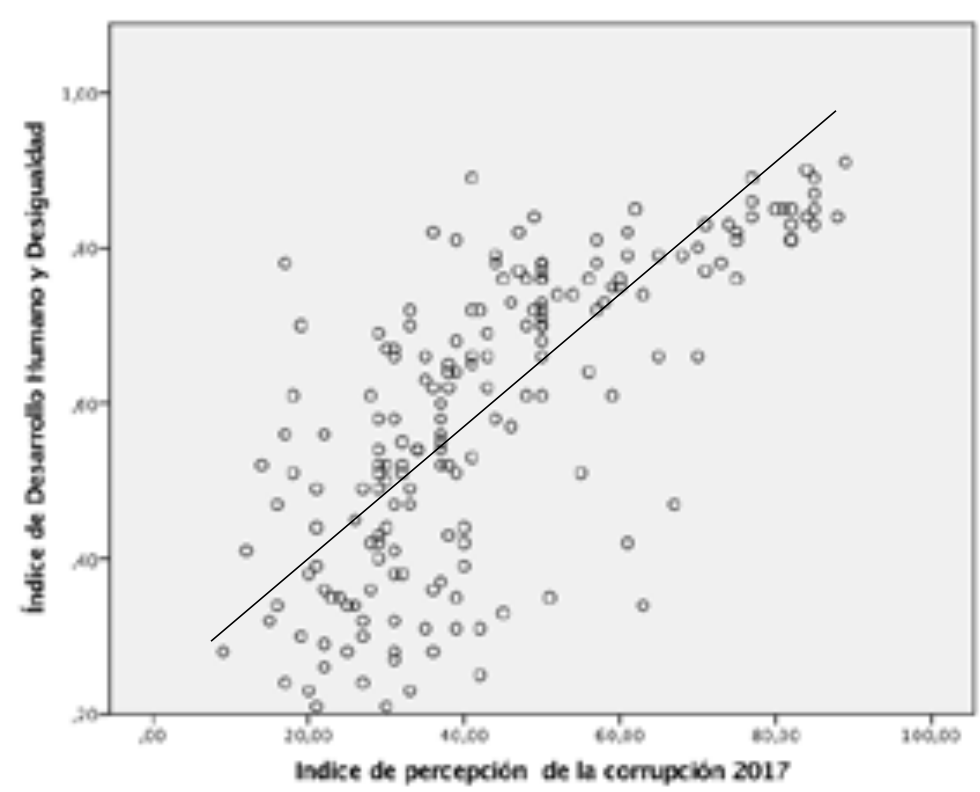

Fuente: Transparencia Internacional. Elaboración propia.

El terrorismo en las sociedades desarrolladas tiene una mayor tendencia a ideologías discriminatorias o excluyentes de carácter étnico, religioso, nacionalista. Como expone S. Pinker, las ideologías que alimentan a estos grupos suelen ser la manifestación del egoísmo humano. Las ideologías nacionalistas «han desencadenado las peores cosas que los individuos se han hecho unos a otros» (Pinker, 2018: 752).

En las sociedades medianamente desarrolladas o en proceso de desarrollo y con un nivel medio de percepción de la corrupción, el terrorismo relacionado con ideologías cuyo objetivo es el establecimiento de un orden sociopolítico de orientación marxista es el más frecuente. En estos casos, la corrupción es una fuerza deslegitimadora de las élites en el poder y los grupos de ideología marxista o maoísta se constituyen como alternativa para la sustitución de las clases corruptas. El terrorismo se legitima entonces como modo de lucha contra el poder abrumador del Estado. El valor de la correlación entre el IPC y la Legitimidad del Estado de Derecho es ( $\mathrm{r}=-0,858$; $\mathrm{s}=0<0,05)$, valor muy alto, como podemos observar (Gráfica 5). La pendiente negativa es el resultado de la puntuación de las variables dado que el Índice de Legitimidad del Estado de Derecho toma valores de 0 a 10 , donde 0 indica que un país es muy respetuoso con el Estado de derecho y 10, nada respetuoso. Así, en la Gráfica 5 observamos que los países muy res- 
petuosos con el Estado de derecho son poco corruptos, en tanto que la corrupción aumenta considerablemente cuando nos alejamos de este orden social.

\section{GRÁFICA 5}

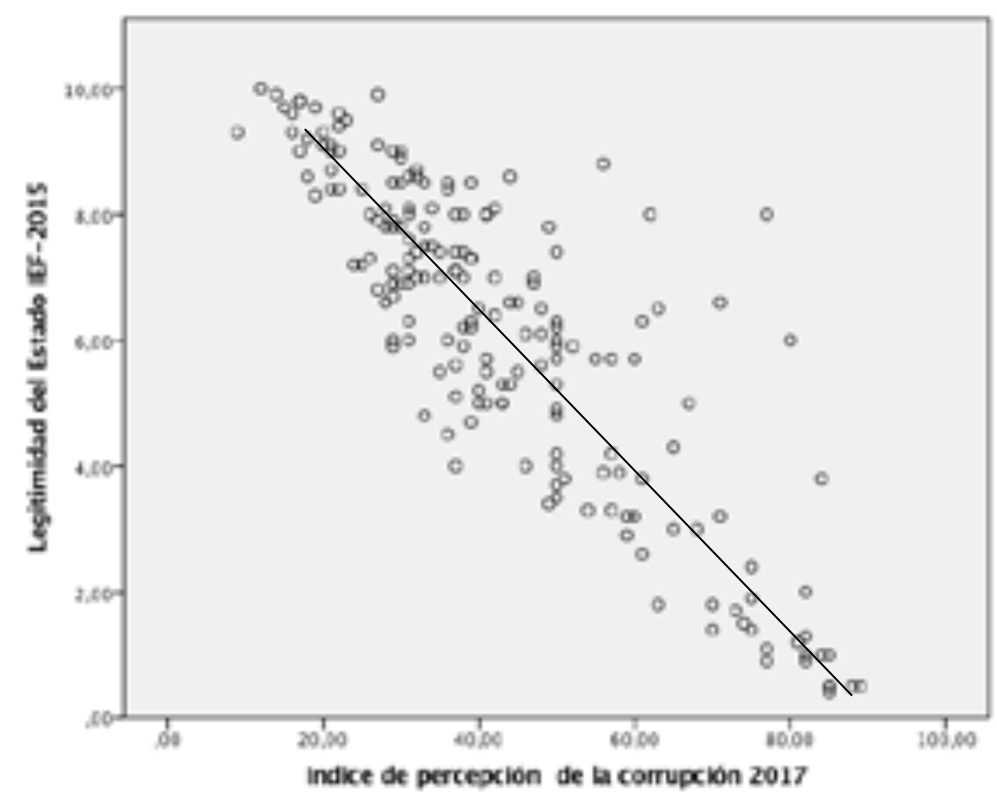

Fuente: Transparencia Internacional y Fondo para la Paz. Elaboración propia.

\section{Terrorismo, inmigrantes y refugiados}

Habitualmente se suele relacionar el terrorismo global con los movimientos migratorios, especialmente el de naturaleza islamista. En una muestra de 667 terroristas de todas las ideologías encontramos que los yihadistas son inmigrantes o hijos de inmigrantes en un $79,7 \%$ de la muestra, en tanto que los que son nacionales representan el $36,8 \%$ (Tabla 9). Por lo general, se suele relacionar a los terroristas musulmanes con individuos en situación de alienación, consecuencia de tener que vivir en un entorno que pone trabas a la mejora de sus condiciones de vida y a manifestaciones culturales propias. Esta situación genera desventajas estructurales entre inmigrantes y autóctonos (Requena y Sanchez-Dominguez, 2011). Sin embargo, no hay correlación entre los porcentajes de población inmigrante recibida por una sociedad y el ITG que soporta ( $\mathrm{r}$ $=-0,172 ; \mathrm{s}=0,02<0,05)$, ambas variables son independientes. 
TABLA 9

Ideología e Inmigrante o descendiente de inmigrantes

\begin{tabular}{|c|c|c|c|}
\hline \multirow{2}{*}{ Ideología } & \multicolumn{2}{|c|}{$\begin{array}{c}\text { Inmigrante o descendiente de } \\
\text { inmigrantes }\end{array}$} & \multirow{2}{*}{ Total } \\
\hline & Nacional & $\begin{array}{l}\text { Inmigrante o hijo } \\
\text { de Inmigrantes }\end{array}$ & \\
\hline Anarquista & $4,4 \%$ & $1,7 \%$ & $2,7 \%$ \\
\hline Independentista / Nacionalista & $23,2 \%$ & $4,1 \%$ & $11,3 \%$ \\
\hline Judío Ultraortodoxo & $1,2 \%$ & $0,7 \%$ & $0,9 \%$ \\
\hline Liberación de El Líbano & $1,6 \%$ & $0,6 \%$ & \\
\hline Liberación de Palestina 9,2\% & $10,7 \%$ & $10,1 \%$ & \\
\hline Marxista & $6,0 \%$ & $1,7 \%$ & $3,3 \%$ \\
\hline Neofascista & $4,4 \%$ & $1,7 \%$ & \\
\hline Neoludita & $0,8 \%$ & $0,2 \%$ & $0,5 \%$ \\
\hline Xenófobo / Racista & $3,2 \%$ & $0,7 \%$ & $1,7 \%$ \\
\hline Yihadista & $36,8 \%$ & $79,7 \%$ & $63,5 \%$ \\
\hline Antiabortista & $2,4 \%$ & $0,9 \%$ & \\
\hline Antisemita & $1,6 \%$ & $0,5 \%$ & $0,9 \%$ \\
\hline Apocalíptica & $0,8 \%$ & $0,3 \%$ & \\
\hline Mafioso / Delincuente & $2,0 \%$ & $0,8 \%$ & \\
\hline Desconocida & $1,6 \%$ & $0,6 \%$ & \\
\hline Feminismo radical & $0,8 \%$ & $0,3 \%$ & \\
\hline Total & $100,0 \%$ & $100,0 \%$ & $100,0 \%$ \\
\hline
\end{tabular}

Fuente: Medios de comunicación. Elaboración propia $(n=667)$.

Si en lugar de población migrante hablamos de población que consta como refugiada en un país, sí encontramos correlación positiva entre el número de refugiados que acoge un país y los ITG que presenta. A mayor número de refugiados, mayor es el valor de su ITG. No obstante, la correlación es muy débil $(\mathrm{r}=-0,172 ; \mathrm{s}=0,02<0,05)$. Ahora bien, hemos de tener presente que el 39,5\% de los refugiados se concentran en la región de Oriente Medio y el 36,3\% en el África Subsahariana (75,8\%). En tanto que las zonas más ricas, América del Norte y la Unión Europea, se reparten el 0,2\%.

En consecuencia, la relación entre terrorismo y migración afecta de modo marginal a los países desarrollados, receptores de un porcentaje elevado de inmigrantes, de los 
que solo una minoría es terrorista, y son los que menos atentados terroristas sufren. En España, la población musulmana ascendía, según los datos del «Estudio demográfico de la población musulmana para 2019» elaborado por la Unión de Comunidades Islámicas de España (UCIDE), a 1.993.675 personas, de las que entre 2004 y 2018 fueron condenadas o murieron por causas de terrorismo 215 (Reinares et al., 2019); esto supone que la probabilidad de encontrar un terrorista entre la población musulmana española es de uno por cada diez mil musulmanes aproximadamente.

Caso contrario ocurre con la población refugiada. En primer lugar, porque estas personas se concentran en los países próximos a las zonas en conflicto y, por tanto, con déficits en sus niveles de desarrollo humano. En segundo lugar, porque entre esta población es más probable encontrar personas muy ideologizadas y vinculadas a los conflictos de los que huyen y, por lo tanto, que desean continuar la lucha.

\section{TERRORISTAS. LA CARA HUMANA DEL TERRORISMO}

Es muy difícil abordar el estudio del terrorismo global partiendo de las historias de vida de los terroristas. Las dificultades de acceso a las fuentes de información son tremendas. En primer lugar, porque estamos hablando de una actividad que, como hecho delictivo, afecta a la seguridad, tanto de los terroristas como de los Estados. Es, por lo tanto, un campo en el que interactúan cuerpos de seguridad, inteligencia, fuerzas armadas, poder judicial, etc.; y, todo en un contexto de discreción o secreto. En segundo lugar, porque la mayoría de los terroristas son, por lógica, personas desconocidas; solamente sabemos de aquellas que tienen trascendencia en los medios de comunicación, y estas son, por lo general, personas que han cometido atentados o han sido detenidas en países desarrollados, pero nada sabemos de la gran mayoría que actúa en zonas de conflicto, por lo que habrá que tener siempre presente el sesgo que conlleva este tipo de investigaciones. En tercer lugar, estudiar el terrorismo suicida complica más las cosas, pues el sujeto ha desaparecido, con lo que toda información sobre ellos estará afectada de los sesgos heurísticos de representatividad y disponibilidad (estereotipos, prejuicios, etc.).

Estas dificultades no han de inhibir a los investigadores interesados en un tema tan actual y vinculado con la violencia social, el conflicto, la antropología cultural, etc. Mediante las fuentes disponibles en internet, bibliografía, trabajos de campo, etc., se puede obtener información más que suficiente para un trabajo de investigación serio. Siendo conscientes en todo momento que en ciencias sociales y del comportamiento, como en otras ciencias, las verdades absolutas no existen. Nos movemos en un universo de teorías, no de teoremas. 
Por lo tanto, en este trabajo no estamos utilizando una muestra estadísticamente significativa. En este sentido, las afirmaciones y conclusiones a las que llegamos solo son extrapolables a esta muestra, es decir, a los 667 individuos catalogados como terroristas conocidos. Por otra parte, y como ya hemos indicado, por la alta representación que tienen en la muestra los terroristas vinculados con el islam, las conclusiones son especialmente representativas para este colectivo.

Aunque los procesos de adoctrinamiento forman parte de la fase de iniciación en todas las ideologías terroristas, es en el terrorismo global de carácter islamista donde ha adquirido una especial relevancia. Para llevarlo a cabo se busca un entorno en el que la persona se encuentre aislada del ambiente cotidiano, siendo las prisiones el hábitat predilecto. En éstas los individuos se encuentran en un estado de necesidades no satisfechas. Del alineamiento entre mensaje y necesidad depende el éxito del proceso.

El contenido de los mensajes ha de ser oportuno, veraz y creíble. Los atentados del 11 de septiembre en Nueva York y los del 11 de marzo en Madrid fueron planificados con oportunidad. La veracidad deriva del contenido doctrinal de la ideología que se presume cierta: textos religiosos, teorías políticas y sociales, derechos étnicos, de raza, históricos, etc. La credibilidad está asociada a la propuesta de una realidad alternativa e incluso virtual que anuncia «intenciones políticas bajo la forma de profecías [...] y un extremado desprecio por los hechos como tales» (Arendt, 2017: 484-485).

Se construyen estructuras con las más diversas configuraciones. Estas tienen en común una organización en anillos o redes cuyo centro está ocupado por el líder. La proximidad al centro dependerá del nivel de identificación con el cuerpo doctrinal y con el líder. Se busca una fusión de identidad con ellos a través de una devoción desproporcionada (Gómez et al., 2016). En una sociedad hipercomunicada como la nuestra, los recursos tecnológicos son imprescindibles para ejercer influencia sobre los individuos. El sociólogo norteamericano Joseph R. Gusfield denomina a esta situación «interacción parasocial» (Laraña, 1996).

La importancia de las relaciones interpersonales la encontramos en los vínculos entre los terroristas y sus familiares y amigos. Nos apoyamos en las tesis del sociólogo norteamericano Mark Granovetter y su teoría de la fuerza de los vínculos débiles, una teoría que está cada vez más vigente en el siglo xxi. Según esta teoría, los lazos o vínculos interpersonales son definidos como conexiones portadoras de información entre personas o individuos. Granovetter defiende que son las relaciones débiles las que portan más información novedosa y, por tanto, son más influyentes a la hora de generar nuevas expectativas.

Esta teoría es ilustrativa para explicar los procesos de radicalización, pero no explica el comportamiento de los terroristas a la hora de tomar decisiones radicales como el suicidio. En este caso, exclusivo del terrorismo vinculado al islam y de liberación tamil de Sri Lanka, las relaciones familiares (vínculos fuertes) adquieren mayor influencia 
sobre la conducta de los terroristas, especialmente las mujeres. La Universidad de Tur$\mathrm{ku}$, en Finlandia, ha realizado un estudio sobre el sacrificio de la mujer en la guerra en el que prueban algunas de las hipótesis de la psicología familiar, concluyendo que las mujeres tienen una especial inclinación a sacrificarse ante una amenaza a los miembros de su grupo o familia (Lynch, 2019).

\section{Perfil general de los terroristas: descripción de una muestra de 667 individuos}

Nos interesa establecer un perfil descriptivo de las características generales de la muestra con la que estamos trabajando. El objetivo es identificar qué aspectos son comunes a todos los tipos de terrorismo y en qué se diferencian. Comenzaremos por la enumeración de las características personales de los terroristas: edad, sexo, lugar de nacimiento y lugar donde ejercen la actividad terrorista.

\section{Edad}

La edad media de los terroristas se sitúa en 31,9 años, con una estimación de intervalo para la media, al $95 \%$ de confianza, de 31,1 a 32,8 años (Tabla 10). Nuestra muestra se encuentra por encima del límite superior del intervalo estimado, luego para un conjunto de mil muestras sería esperable una edad media sensiblemente más baja: 30,17 años. La adecuación de este intervalo la encontramos en los estimadores de la tabla que presentan menos sesgo (Tabla 11).

TABLA 10

\begin{tabular}{|c|c|c|c|c|c|c|c|}
\hline \multicolumn{8}{|c|}{ Edad } \\
\hline & & \multirow{3}{*}{ Estadístico } & \multirow{3}{*}{$\begin{array}{c}\text { Error } \\
\text { estándar }\end{array}$} & \multicolumn{4}{|c|}{ Simulación de muestreo $^{a}$} \\
\hline & & & & \multirow[t]{2}{*}{ Sesgo } & \multirow{2}{*}{$\begin{array}{c}\text { Error } \\
\text { estándar }\end{array}$} & \multicolumn{2}{|c|}{$\begin{array}{c}\text { Intervalo de } \\
\text { confianza al } 95 \%\end{array}$} \\
\hline & & & & & & Inferior & Superior \\
\hline Media & & 31,9504 & 0,42758 & ,00233 & 0,4341 & 31,1085 & 32,8420 \\
\hline \multirow{2}{*}{$\begin{array}{l}95 \% \text { de intervalo } \\
\text { de confianza para } \\
\text { la media }\end{array}$} & $\begin{array}{l}\text { Límite } \\
\text { inferior }\end{array}$ & 31,1108 & & & & & \\
\hline & $\begin{array}{l}\text { Límite } \\
\text { superior }\end{array}$ & 32,7900 & & & & & \\
\hline
\end{tabular}

Fuente: Medios de comunicación. Elaboración propia $(n=667)$. 
TABLA 11

\section{Estimadores M}

\begin{tabular}{|c|c|c|c|c|c|}
\hline & \multirow{3}{*}{ Estadístico } & \multicolumn{4}{|c|}{ Simulación de muestreo $^{\mathrm{e}}$} \\
\hline & & \multirow[t]{2}{*}{ Sesgo } & \multirow{2}{*}{$\begin{array}{c}\text { Error } \\
\text { estándar }\end{array}$} & \multicolumn{2}{|c|}{$\begin{array}{c}\text { Intervalo de confianza } \\
\text { al } 95 \%\end{array}$} \\
\hline & & & & Inferior & Superior \\
\hline Estimador $M$ de Huber ${ }^{a}$ & 30,1792 & ,0453 & ,4795 & 29,3286 & 31,1862 \\
\hline
\end{tabular}

Fuente: Medios de comunicación. Elaboración propia $(n=667)$.

La muestra sigue una distribución normal, prueba de Kolmogorov-Smirnov (Tabla 12 y Gráfica 6).

TABLA 12

\begin{tabular}{cccccccc}
\hline \multicolumn{6}{c}{ Pruebas de normalidad para Edad } \\
\hline & \multicolumn{3}{c}{ Kolmogorov-Smirnova } & \multicolumn{3}{c}{ Shapiro-Wilk } \\
\cline { 2 - 7 } & Estadístico & gl & Sig. & Estadístico & gl & Sig. \\
\hline \multirow{2}{*}{ Edad } & 0,120 & $\mathbf{6 6 5}$ & $\mathbf{0 , 0 0 0}$ & 0,935 & 665 & $\mathbf{0 , 0 0 0}$ \\
\hline
\end{tabular}

Fuente: Medios de comunicación. Elaboración propia $(n=667)$.

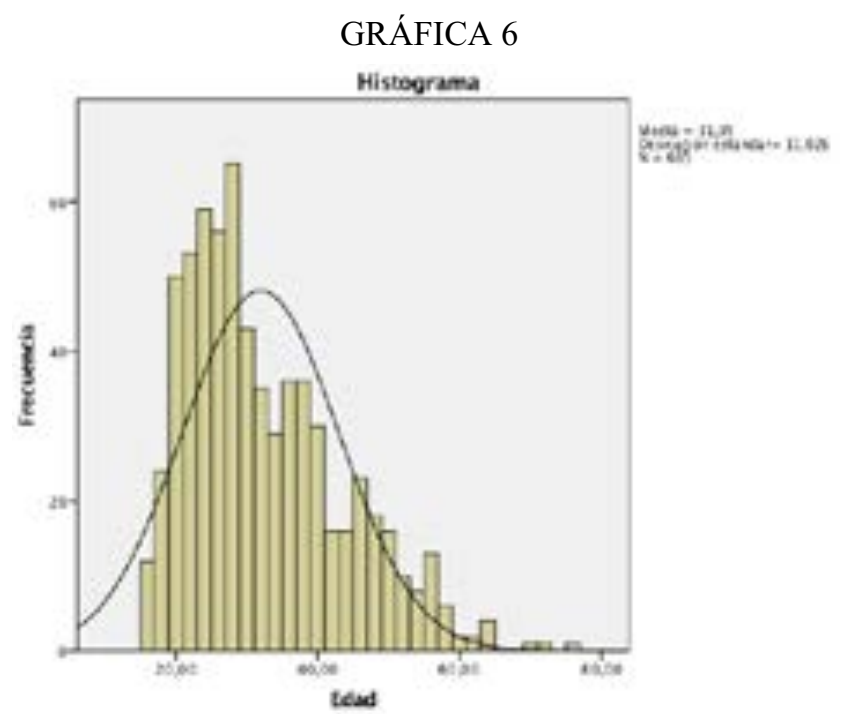

Fuente: Medios de comunicación. Elaboración propia $(n=667)$. 
Tenemos por tanto una población de terroristas jóvenes dispuestos a la acción violenta y abiertos a la manipulación mediante el convencimiento de que están dedicando sus vidas a una causa noble como hombres y mujeres valientes. Pero la valentía, dice Aristóteles, no es «morir por huir de la pobreza o de la pasión o de algo doloroso, esto no es de un hombre valiente, sino más bien de un cobarde: blandura es eludir las situaciones duras, y aquel que lo hace aguanta no porque sea bueno, sino por huir de lo malo» (Aristóteles, 2012: 82).

Sexo

El $17,7 \%$ de la muestra son mujeres y el $82,3 \%$, hombres. Las mujeres son un poco más jóvenes que los hombres; su edad media es de 29,8 años, y la de los hombres, 32,41 años.

En cuanto al lugar de nacimiento (Tabla 13), hemos considerado solo aquellos porcentajes mayores que uno. El 10,1\% de los terroristas de la muestra son palestinos, es el terrorismo más conocido y estudiado, tanto por la espectacularidad e internacionalidad de sus acciones como por el origen del conflicto. España aporta el 9,9\% de los terroristas de la muestra. Lógicamente, los terroristas que actúan o actuaron en nuestro país tienen gran repercusión en los medios de comunicación. El 11,7\% ha nacido en países de importancia por su pasado colonial, Francia y Reino Unido. Los que menos aportan a la muestra son los procedentes de países en conflicto, los terroristas anónimos. El $37,7 \%$ de los terroristas de la muestra ha nacido en el mismo país en el que han cometido sus acciones violentas; el 62,3\% nacieron en países distintos de los que actúan.

TABLA 13

Porcentaje de terroristas por lugar de nacimiento

\begin{tabular}{lclc}
\hline & $\mathbf{\%}>\mathbf{1}$ & & $\mathbf{\%}>\mathbf{1}$ \\
\hline Afganistán & 1,2 & Italia & 1,4 \\
\hline Alemania & 2,0 & Jordania & 1,1 \\
\hline Arabia Saudita & 4,2 & Líbano & 2,1 \\
\hline Argelia & 6,6 & Marruecos & 7,8 \\
\hline Bélgica & 1,4 & Pakistán & 3,2 \\
\hline Egipto & 3,9 & Palestina & $\mathbf{1 0 , 1}$ \\
\hline
\end{tabular}




\begin{tabular}{lclc}
\hline & $\mathbf{0}>\mathbf{1}$ & & $\mathbf{\%} \mathbf{1}$ \\
\hline España & $\mathbf{9 , 9}$ & Reino Unido & 7,2 \\
\hline Estados Unidos & 5,7 & Rusia & 3,8 \\
\hline Francia & $\mathbf{4 , 5}$ & Siria & 2,0 \\
\hline India & 1,2 & Túnez & 1,5 \\
\hline Iraq & 1,8 & Turquía & 1,1 \\
\hline Irán & 1,2 & & \\
\hline
\end{tabular}

Fuente: Medios de comunicación. Elaboración propia $(n=667)$.

\section{Estado Civil}

El 44,8\% de los terroristas de la muestra estaban o están casados/as; el $49 \%$, solteros/as; el 3\%, divorciados/as; y el 3,7\%, viudos/as. Las mujeres destacan sobre los hombres en porcentaje de viudas y divorciadas (Tabla 14).

TABLA 14

Tabla Estado Civil y Sexo

\begin{tabular}{lrrr} 
& \multicolumn{2}{c}{ Sexo } & Total \\
\cline { 2 - 3 } & Femenino & Masculino & \\
\hline Casado/a & $34,7 \%$ & $47,0 \%$ & $44,8 \%$ \\
\hline Divorciado/a & $8,5 \%$ & $1,8 \%$ & $3,0 \%$ \\
\hline Soltero/a & $39,8 \%$ & $51,0 \%$ & $49,0 \%$ \\
\hline Viudo/a & $16,9 \%$ & $0,2 \%$ & $3,2 \%$ \\
\hline Total & $100,0 \%$ & $100,0 \%$ & $100,0 \%$
\end{tabular}

Fuente: Medios de comunicación. Elaboración propia $(n=667)$.

Un 40,5\% de los terroristas ha formado algún tipo de núcleo familiar con la presencia de hijos.

El 53,4\% de los terroristas de la muestra ya han fallecido y viven el 46,6\%. En cuanto a las causas de la muerte, los que eligen la autoinmolación son los más jóvenes, seguidos de los que mueren en acción de guerra y enfrentamientos con las fuerzas de seguri- 
dad. Los porcentajes de fallecidos por sexos son similares para cada grupo: el 45,8 \% del total de mujeres y el $55 \%$ del de hombres. Con respecto a las causas de la muerte: para las mujeres la más frecuente ha sido la autoinmolación 34,7\%, superando al grupo de los hombres, $14,4 \%$. Para los hombres las muertes más frecuentes han sido por enfrentamiento a fuerzas de seguridad o acciones de guerra $18,1 \%$, el 7,6 \% han sido eliminados por Estados Unidos, Israel o Francia, y el 7,9\%, ejecutados por el Estado (Tabla 15).

TABLA 15

\begin{tabular}{lc}
\hline \multicolumn{1}{c}{ Causa de la muerte } & Edad Media \\
\hline Accidente & 33,43 \\
\hline Enfermedad & 34,61 \\
\hline Enfrentamiento F. Seguridad & 29,21 \\
\hline Muerte Natural & 32,33 \\
\hline Suicidio & 32,38 \\
\hline Acción de Guerra & $\mathbf{2 8 , 1 3}$ \\
\hline Asesinato & 38,17 \\
\hline Atentado & 32,75 \\
\hline Autoinmolación & $\mathbf{2 6 , 8 3}$ \\
\hline Ejecución por Estado & 31,95 \\
\hline Eliminación por Israel & 36,43 \\
\hline Eliminación por EE. UU. & 37,50 \\
\hline Eliminación Francia & 56,00 \\
Fuente: Medios de comunicación. Elaboración propia $(\mathrm{n}=667)$. &
\end{tabular}

Ideologías y niveles de estudio

La ideología más representativa es la yihadista, con un 63,3\%. De los cuales un $64,3 \%$ son hombres y el 37,3\%, mujeres. La liberación de Palestina representa $22 \%$ y el nacionalismo independentista, otro $22 \%$.

En lo referente al nivel de estudios de los terroristas apenas hay diferencias significativas entre hombres y mujeres, siendo el porcentaje de mujeres con estudios universi- 
tarios, dentro de su grupo, mayor que el de los hombres (Tabla 16). La ideología con más mujeres universitarias está relacionada con la guerra del Líbano y la liberación de Palestina, seguido del terrorismo independentista nacionalista. En el caso de los hombres, donde más universitarios se concentran es en las ideologías políticas de extrema izquierda y de extrema derecha, así como en los movimientos racistas y xenófobos.

TABLA 16

Tabla cruzada Nivel de Estudios y Sexo

\begin{tabular}{|c|c|c|c|}
\hline \multirow{2}{*}{ Nivel de Estudios } & \multicolumn{2}{|c|}{ Sexo } & \multirow{2}{*}{ Total } \\
\hline & Femenino & Masculino & \\
\hline Elementales & $49,2 \%$ & $54,7 \%$ & $53,7 \%$ \\
\hline Superiores & $16,9 \%$ & $13,7 \%$ & $14,3 \%$ \\
\hline Universitarios & $33,9 \%$ & $31,6 \%$ & $32,0 \%$ \\
\hline Total & $100,0 \%$ & $100,0 \%$ & $100,0 \%$ \\
\hline
\end{tabular}

Fuente: Medios de comunicación. Elaboración propia $(\mathrm{n}=667)$.

\section{Participación en atentados}

El 58,5\% de las mujeres y el $62,6 \%$ de los hombres han participado de forma directa en atentados terroristas, y, de estos, el 48,3\% de las mujeres y el 56,1\% de los hombres han provocado víctimas mortales. Con respecto a las armas utilizadas en los atentados, las mujeres se inclinan mayoritariamente por los artefactos explosivos seguidos de las armas de fuego. Los hombres son mucho más diversos y utilizan todos los medios o armas a su alcance. En cuanto a los objetivos, para todas las ideologías destacan mayoritariamente los de carácter indiscriminado.

\section{Trastornos psicológicos}

Los trastornos psicológicos apenas tienen representación en la muestra. En el 18\% de las mujeres los medios de comunicación señalan algún tipo de trastorno psicológico, destacando la depresión y el trastorno psicopático, pero sin aclarar si estaban debidamente diagnosticados. En el caso de los hombres ocurre lo mismo, pero los trastornos tienen menor representación: solamente en el $9 \%$ de la muestra de hombres se cita algún tipo de trastorno, entre los que destacan el trastorno psicopático, las alteraciones diversas de la conducta y la personalidad, y el consumo de estupefacientes. 


\section{Estatus social y marginalidad}

Nos planteamos la siguiente cuestión: ¿proceden los terroristas de las clases marginales de la sociedad o, por el contrario, se distribuyen de forma más o menos homogénea por la estructura social?

El concepto de marginalidad hace referencia a la situación de un individuo que se encuentra fuera de la estructura social o, en un estrato de ésta, que es excluido por ser disfuncional para el correcto funcionamiento de una sociedad en base a sus valores y creencias culturales.

Las sociedades democráticas se caracterizan por garantizar a los individuos unos derechos y libertades fundamentales que posibiliten su mejora social. En principio, cualquier individuo puede modificar su posición en la sociedad sin que sus posibilidades se vean coartadas por razones de sexo, creencias y opiniones, raza, etnia, etc. Sin embargo, la realidad es que las oportunidades de movilidad no se distribuyen de forma homogénea entre los estratos sociales (Sandel, 2020). Las oportunidades de mejora están en función de la cantidad de capital ${ }^{9}$ acumulado por un estrato o élite. Este capital siempre será un recurso crítico, necesario y muy estimado por el grupo (Bourdieu, 2008).

Como destaca el profesor Trujillo, las personas que se encuentra en una situación de marginalidad real o percibida tienen una mayor probabilidad de caer bajo el control de acontecimientos vitales estresantes. Esta situación puede provocar estados de indefensión ante las amenazas que el ambiente cotidiano presentan al individuo. Se produce un efecto de pérdida de contacto entre la persona y la realidad, y el individuo se aísla socialmente. Como resultado, nos encontramos con personas que manifiestan un estado de agitación hipervigilante, irritable y agresiva, sin motivación hacia logros personales y, por lo tanto, fáciles de persuadir (Trujillo, 2004).

Estas conclusiones hay que entenderlas en términos de probabilidad y no de una relación directa causa-efecto. Las personas que viven en situaciones de marginalidad y optan por el terrorismo son una minoría. Como ya hemos comentado, relacionar pobreza o marginalidad con terrorismo responde más a un sesgo heurístico de disponibilidad que a una realidad racional. Daniel Kahneman denomina a esta forma de razonar «pensamiento automático» (Kahneman, 2013). Con esto no pretendemos banalizar la amenaza terrorista, pues el terrorismo no es una estrategia de cantidad, sino de calidad; un solo atentado puede representar una gran conmoción social. Pero sí enfrentar la realidad al tópico y a los prejuicios.

${ }^{9}$ Nos referimos al término capital en el sentido y con la significación que le da P. Bourdieu en su teoría de los campos sociales. 
En nuestra muestra solo un 2,6\% de los terroristas se encuentra en situación de pobreza, es decir, que vivían de los subsidios sociales; el 45,4\% procede de un estatus socioeconómico bajo: obreros no cualificados, etc.; el 18,2\%, medio bajo; y el 33,8\% procede de una situación económicamente desahogada, ellos o sus familias tienen estudios mayoritariamente universitarios y/o profesiones cualificadas, negocios y, en el $2,7 \%$ de los casos, rentas muy altas (Tabla 17).

\section{TABLA 17}

Tabla cruzada Nivel de Estudios y Estatus Socioeconómico

\begin{tabular}{|c|c|c|c|c|c|c|c|}
\hline \multirow[b]{2}{*}{ Estudios } & \multicolumn{6}{|c|}{ Estatus Socioeconómico } & \multirow[b]{2}{*}{ Total } \\
\hline & Alto & $\begin{array}{c}\text { Medio } \\
\text { Alto }\end{array}$ & Medio & $\begin{array}{c}\text { Medio } \\
\text { Bajo }\end{array}$ & Bajo & Pobreza & \\
\hline Elementales & $0,2 \%$ & $0,3 \%$ & $5,9 \%$ & $6,8 \%$ & $38,5 \%$ & $2,1 \%$ & $53,7 \%$ \\
\hline Superiores & $0,3 \%$ & $0,2 \%$ & $3,3 \%$ & $5,4 \%$ & $4,8 \%$ & $0,3 \%$ & $14,3 \%$ \\
\hline Universitarios & $2,3 \%$ & $4,7 \%$ & $16,8 \%$ & $6,0 \%$ & $2,1 \%$ & $0,2 \%$ & $32,0 \%$ \\
\hline Total & $2,7 \%$ & $5,1 \%$ & $26,0 \%$ & $18,2 \%$ & $45,4 \%$ & $2,6 \%$ & $100,0 \%$ \\
\hline
\end{tabular}

Fuente: Medios de comunicación. Elaboración propia $(n=667)$.

En la Tabla 18 mostramos la distribución de los terroristas de la muestra en función del estatus socioeconómico y la ideología. Los terroristas de ideología nacionalista-independentista proceden, en su mayoría, del estrato socioeconómico medio-bajo. Sin embargo, en el yihadismo y en los grupos palestinos predominan individuos de estatus socioeconómico bajo.

\section{TABLA 18}

Tabla cruzada Ideología/Estatus Socioeconómico

\begin{tabular}{lccccccc}
\hline \multicolumn{7}{c}{ E del total } \\
\hline & Alta & $\begin{array}{c}\text { Medio } \\
\text { Alto }\end{array}$ & Medio & $\begin{array}{c}\text { Medio } \\
\text { Bajo }\end{array}$ & Baja & Pobreza & Total \\
\cline { 2 - 8 } & 0,3 & & 0,2 & 0,3 & 1,2 & 0,8 & 2,7 \\
\hline Anarquista & & 0,5 & 3,2 & 5,0 & 2,7 & 11,3 \\
\hline Independencitista/Nacionalista & 0,2 & 0,2 & 0,6 & & & 0,9 \\
\hline Judío Ultraortodoxo & & 0,2 & 0,2 & 0,2 & 0,2 & 0,6 \\
\hline Liberación de El Líbano & 0,6 & 0,3 & 2,0 & 2,0 & 5,3 & 10,1 \\
\hline Liberación de Palestina & & & & & & \\
\hline
\end{tabular}




\begin{tabular}{|c|c|c|c|c|c|c|c|}
\hline \multicolumn{8}{|c|}{$\%$ del total } \\
\hline & \multicolumn{6}{|c|}{ Estatus Socioeconómico } & \multirow[b]{2}{*}{ Total } \\
\hline & Alta & $\begin{array}{c}\text { Medio } \\
\text { Alto }\end{array}$ & Medio & $\begin{array}{c}\text { Medio } \\
\text { Bajo }\end{array}$ & Baja & Pobreza & \\
\hline Marxista & 0,3 & 0,6 & 1,4 & 0,6 & 0,5 & & 3,3 \\
\hline Neofascista & & 0,6 & 0,3 & 0,5 & 0,3 & & 1,7 \\
\hline Neoludita & 0,2 & & 0,2 & & 0,2 & & 0,5 \\
\hline Xenófobo/Racista & & 0,2 & 1,1 & 0,3 & 0,2 & & 1,7 \\
\hline Yihadista & 1,1 & 2,4 & 15,1 & 8,9 & 34,4 & 1,7 & 63,5 \\
\hline Antiabortista & & & 0,2 & 0,5 & 0,3 & & 0,9 \\
\hline Antisemita & 0,2 & & 0,6 & & 0,2 & & 0,9 \\
\hline Apocalíptica & & 0,2 & 0,2 & & & & 0,3 \\
\hline Mafioso/Delincuente & & & 0,6 & & 0,2 & & 0,8 \\
\hline Desconocida & & & 0,2 & 0,2 & 0,3 & & 0,6 \\
\hline Feminismo radical & & 0,2 & & & & 0,2 & 0,3 \\
\hline Total & 2,7 & 5,1 & 25,6 & 18,3 & 45,7 & 2,6 & 100,0 \\
\hline
\end{tabular}

Fuente: Medios de comunicación. Elaboración propia $(n=667)$.

También encontramos que hay relación de dependencia entre el hecho de ser terrorista y el IDH-D del país de procedencia. El resultado de la prueba de $X^{2}$ (chi-cuadrado) para la Tabla 19 nos permite rechazar la hipótesis de independencia (Tabla 20).

\section{TABLA 19}

Tabla cruzada Nivel del Índice de Desarrollo Humano país de actividad y Estatus Socioeconómico de los terroristas

\begin{tabular}{|c|c|c|c|c|c|c|c|c|}
\hline & & \multicolumn{6}{|c|}{ Estatus Socioeconómico del terrorista } & \multirow[b]{2}{*}{ Total } \\
\hline & & Alto & $\begin{array}{c}\text { Medio } \\
\text { Alto }\end{array}$ & Medio & $\begin{array}{c}\text { Medio } \\
\text { Bajo }\end{array}$ & Bajo & Pobreza & \\
\hline \multirow{4}{*}{$\begin{array}{l}\text { Nivel del } \\
\text { IDH del país } \\
\text { de actividad } \\
\text { del terrorista }\end{array}$} & IDH Muy Alto & $0,1 \%$ & $0,6 \%$ & $5,7 \%$ & $2,8 \%$ & $8,1 \%$ & $0,4 \%$ & $17,8 \%$ \\
\hline & IDH Alto & $1,9 \%$ & $2,5 \%$ & $8,2 \%$ & $9,1 \%$ & $20,7 \%$ & $1,3 \%$ & $43,9 \%$ \\
\hline & IDH Medio & $0,3 \%$ & $0,7 \%$ & $3,6 \%$ & $1,9 \%$ & $6,1 \%$ & $12,7 \%$ & \\
\hline & IDH Bajo & $0,3 \%$ & $1,0 \%$ & $8,5 \%$ & $4,5 \%$ & $10,3 \%$ & $0,7 \%$ & $25,5 \%$ \\
\hline \multicolumn{2}{|c|}{ Total } & $2,7 \%$ & $4,9 \%$ & $26,1 \%$ & $18,4 \%$ & $45,3 \%$ & $2,5 \%$ & $100,0 \%$ \\
\hline
\end{tabular}

Fuente: Medios de comunicación. Elaboración propia $(n=667)$. 
TABLA 20

Pruebas de chi-cuadrado

\begin{tabular}{lccc}
\hline & Valor & df & Significación asintótica (bilateral) \\
\hline Chi-cuadrado de Pearson & $29,163^{\mathrm{a}}$ & 15 & $0,015<0,05$ \\
\hline Razón de verosimilitud & 32,075 & 15 & 0,006 \\
\hline Asociación lineal por lineal & 2,964 & 1 & 0,085 \\
\hline N de casos válidos & 667 & & \\
\hline
\end{tabular}

a 7 casillas $(29,2 \%)$ han esperado un recuento menor que 5. El recuento mínimo esperado es 3,62.

Fuente: Medios de comunicación. Elaboración propia $(\mathrm{n}=667)$.

Una creencia muy extendida entre amplios sectores sociales presume una estrecha relación entre inmigración, delincuencia y terrorismo de última generación o yihadista. Sin embargo, esta creencia, como ya hemos comentado, es una visión estereotipada que no cuenta con un respaldo sólido en el ámbito de la investigación social (Martínez y Lee, 2004). Como vemos en la Tabla 21, la correlación entre inmigración y homicidios tiene pendiente negativa, es decir, en las sociedades en las que el porcentaje de inmigración aumenta, el índice de homicidios disminuye. Y lo mismo podemos decir de la relación entre la inmigración y el ITG (Tabla 22).

\section{TABLA 21}

Correlación \% Inmigración sobre población total e Índice de homicidios por 100.000 h. (IH)

\begin{tabular}{clc}
\hline \multirow{2}{*}{$\begin{array}{c}\text { \% población inmigrante } \\
\text { sobre población total }\end{array}$} & Correlación de Pearson & $\begin{array}{c}\text { Índice de Homicidios } \\
\text { por } \mathbf{1 0 0 . 0 0 0 ~} \mathbf{H .} .\end{array}$ \\
\cline { 2 - 3 } & Sig. (bilateral) & $-0,211^{* *}$ \\
\cline { 2 - 3 } & $\mathrm{N}$ & $0,004<0,05$ \\
\hline
\end{tabular}

** La correlación es significativa en el nivel 0,01 (bilateral).

Fuente: Banco Mundial. Elaboración propia.

TABLA 22

Correlación \% Inmigración sobre población total e ITG ITG

\begin{tabular}{clc}
\hline & & ITG \\
\hline \multirow{2}{*}{$\begin{array}{c}\text { \% población inmigrante } \\
\text { sobre población total }\end{array}$} & Correlación de Pearson & $-0,172^{*}$ \\
\cline { 2 - 3 } & Sig. (bilateral) & $0,020<0,05$ \\
\cline { 2 - 3 } & $\mathrm{N}$ & 185 \\
\hline
\end{tabular}

* La correlación es significativa en el nivel 0,05 (bilateral).

Fuente: Banco Mundial. Elaboración propia. 
En la muestra de terroristas con la que estamos trabajando, sólo el 2,5\% de las mujeres y el 10,9\% de los hombres tienen antecedentes por delincuencia común: tráfico de drogas y homicidios. El resto, $39 \%$ de las mujeres y $38 \%$ de los hombres, ha sido detenido por delitos de terrorismo. Por lo tanto, respondiendo a la pregunta que nos hacíamos al comienzo de este apartado, no podemos concluir que haya una relación significativa entre inmigración, marginalidad y el hecho de ser terrorista.

\section{Terroristas suicidas}

El terrorismo suicida era un fenómeno sin apenas relevancia hasta la aparición del yihadismo. Tuvo sus primeras manifestaciones en el terrorismo palestino y posteriormente con las guerras del Líbano, donde se dieron los primeros suicidios ${ }^{10}$.

El psicólogo especialista en suicidio Israel Orbach define al suicida como una persona que no puede controlar su angustia y, por tanto, experimenta un sufrimiento intolerable que acarrea depresión, ansiedad, miedo y desesperación. «El individuo vive en la creencia de que las circunstancias que le rodean son extremas, y esta situación de angustia psicológica puede acelerar el proceso de suicidio» (Victor, 2004: 293-294). No obstante, este no es el caso general de los terroristas de nuestra muestra, como ya hemos comentado; solo unos pocos manifiestan algún tipo de trastorno psicológicos.

Entre las características de los terroristas de nuestra muestra, suicidas o no, destacan: tener un nivel de estudios bajo, no solteros sin hijos y con relaciones de familia o amistad dentro del ámbito terrorista. En cuanto a las particularidades de los terroristas suicidas destacamos: una mayor presencia de la mujer; notable proporción de menores de veinticinco años; importante proporción de inmigrantes; creciente importancia de la ideologización yihadista reciente, aunque no de forma determinante; y un estatus socioeconómico mayor (Gráfica 7).

El terrorismo suicida está relacionado con la ideología religiosa en un $81 \%$, especialmente con el yihadismo. Si una persona se quita la vida como un mártir, si muere por Dios, está devolviendo a Dios algo que Este le ha prestado, «algo altamente valorado que equipara al mártir con el Profeta» (Victor, 2004: 253).

${ }^{10}$ Aunque históricamente ha habido organizaciones que lanzaban a sus adeptos a cumplir misiones en las que existía una alta probabilidad de muerte de los ejecutores, como los sicarios judíos durante la ocupación romana, o los famosos hashshashin seguidores de Hassan-i Sabbah, estos se producen en unas circunstancias en las que la muerte del asesino no era irremediable. 


\section{GRÁFICA 7}

Perfil de terroristas suicidas y no suicidas.

Consistencia de las condiciones

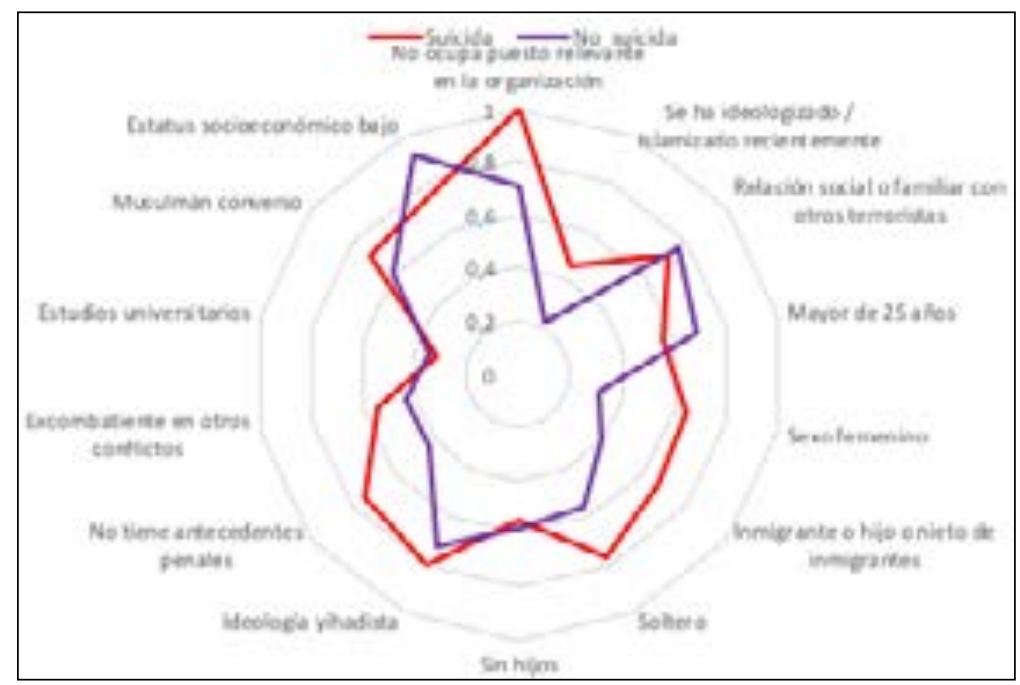

Fuente: Bibliografía y prensa digital. Elaboración propia $(n=667)$.

\section{Mujer terrorista}

La participación de la mujer en el terrorismo ha sido una constante a lo largo de la historia, en un principio vinculadas a grupos sufragistas y movimientos por los derechos de las mujeres, anarcosindicalistas y revolucionarios de izquierda, como la actriz germano-británica Kitty Marion; la periodista revolucionaria alemana de la Fracción del Ejército Rojo Ulrike Meinhof, una mujer con trastornos psicológicos que se suicidó en prisión en 1976; la norteamericana Susan Stern, del Frente de Liberación de Seattle, que murió como consecuencia de los excesos con las drogas en 1976; la también norteamericana y todavía reclamada a Cuba por Estados Unidos Joanne Chesimard, del Ejército de Liberación Negro; la irlandesa Donna Maguire, del IRA, detenida en 2015 en España; Fusako Shigenobu, líder del Ejército Rojo Japonés; Elena Iparraguirre, líder femenina peruana de Sendero Luminoso; Inés del Río Prada e Idoia López Riaño y otras tantas terroristas de ETA en España, etc. En todo caso, las mujeres terroristas eran una excepción y, por lo general, tenían algún tipo de relación que las vinculaba a los grupos terroristas. 
La relación de la mujer con la violencia, en este caso con el terrorismo, es motivo de discusión. Por lo general, es aceptado que las mujeres tienen una menor inclinación biológica y social a la violencia, debida a sus menores niveles de testosterona y a los roles y condicionamientos socioculturales que el proceso de civilización da a la mujer. Entre los chimpancés las hembras no suelen luchar, pero son instigadoras de luchas entre los machos y también apaciguadoras de machos frustrados por una derrota (De Waal, 1993). S. Pinker hace referencia a las palabras de Tsutomu Yamaguchi, ingeniero japonés que sobrevivió a las dos bombas nucleares lanzadas en 1945 sobre Japón. «Las únicas personas que deberían poder gobernar países con armas nucleares son las madres, las que aún están dando el pecho a sus bebés» (Pinker, 2018: 918).

\section{GRÁFICA 8}

Tasa de homicidios y criminalidad en España por sexos

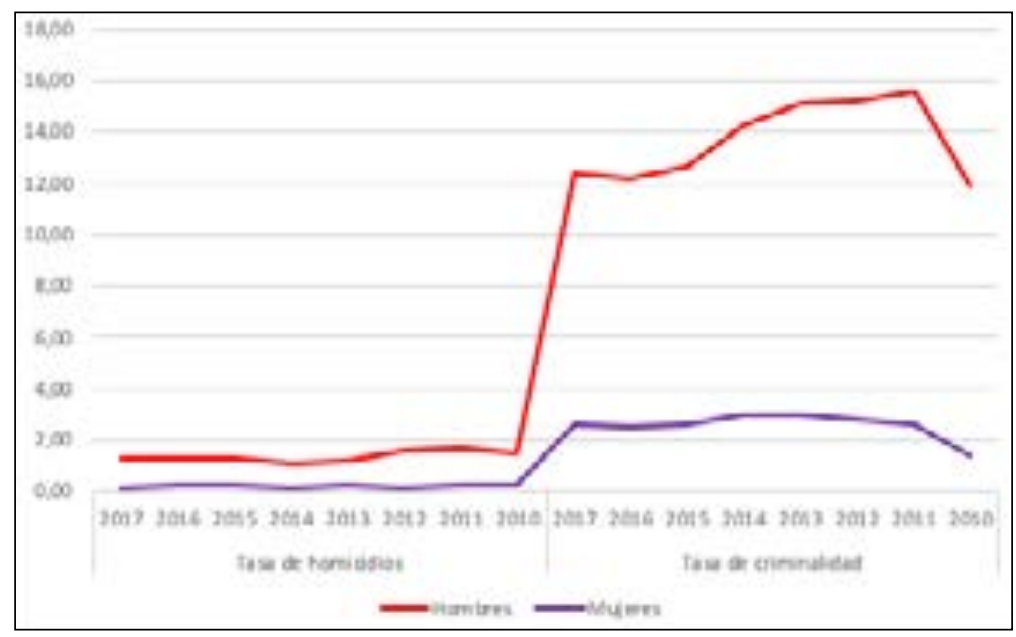

Fuente: Instituto Nacional de Estadística (INE).

A nivel global, la tasa de homicidios de hombres es casi cuatro veces mayor que la de mujeres (9,9 contra 2,7 por cada 100.000), siendo más en América (30 por cada 100.000 hombres), que es casi siete veces mayor que las de Asia, Europa y Oceanía (todas por debajo de 4,5 por cada 100.000 hombres) ${ }^{11}$ (Gráfica 11).

Su mayor representatividad la encontramos en relación con el terrorismo en Oriente Medio, concretamente con el conflicto palestino-israelí. Leila Khaled fue la primera mujer que participó en acciones terroristas. Barbara Victor defiende la tesis de que el

${ }^{11} \mathrm{https} / / /$ www.unodc.org/documents/gsh/pdfs/GLOBAL_HOMICIDE_Report_ExSum_spanish.pdf 
terrorismo suicida actual de mujeres palestinas responde a un feminismo mal entendido; este encumbró a Wafa Idriss, primera mujer suicida palestina, como ejemplo de mujer palestina liberada que lucha igual que un hombre. Sin embargo, detrás de esta visión romántica se encuentra una realidad menos épica. Detrás de la imagen de Wafa Idriss, que aparece retocada con elementos religiosos, se encuentra una vida traumática consecuencia de abusos, abandonos, malos tratos, depresión, rabia incontrolada por la pérdida de seres queridos, etc. Generalmente «eran mujeres que tenían problemas familiares que hacían insoportable su vida» (Victor, 2004: 22).

En la Gráfica 12 observamos los perfiles de características de hombres y mujeres que han sido catalogados como terroristas de distintos tipos e ideologías. Los elementos diferenciales los encontramos en una mayor tendencia de las mujeres al suicidio; las mujeres también suelen tenar más relaciones familiares o de amistad con otros terroristas. Es de destacar que, en el caso de las terroristas palestinas, generalmente eran reclutadas por miembros de confianza de la familia, normalmente hombres con capacidad de decidir sobre su vida, especialmente cuando mediaban conflictos de honor; «el único camino para redimirse ellas mismas de alguna trasgresión moral y salvar el honor de su familia era morir como una mártir» (Victor, 2004: 22-23).

En nuestra muestra, el $62,5 \%$ de las terroristas que se suicidaron tenían relaciones familiares con otros terroristas, frente al $32,9 \%$ de los hombres. Por el contrario, entre los que no tienen relaciones familiares con otros terroristas, el 18,2\% son mujeres y el $81,8 \%$, hombres (Tabla 23).

TABLA 23

\begin{tabular}{|c|c|c|c|c|c|}
\hline & & & & \multicolumn{2}{|c|}{ Relaciones Familiares } \\
\hline \multicolumn{4}{|c|}{ Relaciones familiares y terrorismo suicida } & Sí & No \\
\hline & & & & $\%$ de $\mathbf{N}$ columnas & $\%$ de $\mathrm{N}$ columnas \\
\hline \multirow[t]{4}{*}{ Terrorista Suicida } & Sí & Sexo & Femenino & 62,5 & 18,2 \\
\hline & & & Masculino & 37,5 & 81,8 \\
\hline & No & Sexo & Femenino & 35,4 & 10,0 \\
\hline & & & Masculino & 64,6 & 90,0 \\
\hline
\end{tabular}

Fuente: Banco Mundial. Elaboración propia. 


\section{GRÁFICA 9}

Características principales de hombres y mujeres terroristas.

Consistencia de las condiciones

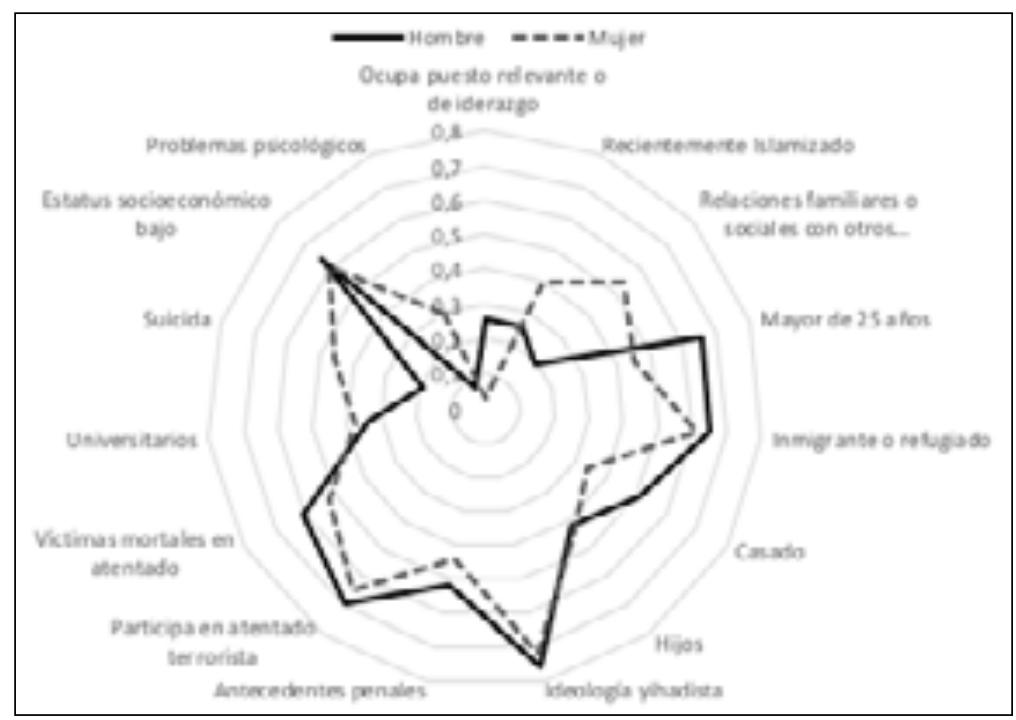

Fuente: Bibliografía y prensa digital. Elaboración propia $(n=667)$.

\section{CONCLUSIONES}

El terrorismo es una forma de violencia política que se vertebra en los tres pilares que constituyen la vida social: la psicología de los individuos, concretamente actuando sobre el sistema cognitivo y emocional; las deficiencias estructurales, especialmente aquellas que implican situaciones de injusticia; $y$, en tercer lugar, pero no menos importante, en los procesos históricos en los que se configuran las ideologías, entendidas estas en su significado perverso de conjunto de ideas que tienen como finalidad la manipulación de las personas por entes ajenos a ellas y con el fin de alcanzar fines perjudiciales a sus intereses. Sobre ellas se construyen los discursos de legitimación de la violencia.

En relación con factores socioestructurales, el terrorismo encuentra mayor acogida en sociedades con un bajo desarrollo humano y en las que la corrupción forma parte de la vida política. Sin embargo, no está relacionado con la pobreza extrema. La violencia política surge cuando una serie de grupos o estratos sociales perciben que su situación es injusta o cuando sus niveles de bienestar decrecen, todo ello referido a un pasado que se considera glorioso y al que, retornando, todos los males presentes desaparecerían. En 
el caso de la pobreza extrema, es tal la necesidad de satisfacción de las necesidades básicas y vitales que no queda tiempo ni energía para la acción social.

La procedencia de los terroristas es mayoritariamente de las clases medias bajas y bajas, pero no pobres extremos. Tampoco hay relación entre terrorismo e inmigración. Pero sí la hay entre terrorismo y población de refugiados, porque estos se encuentran mayoritariamente concentrados en zonas de conflicto donde el terrorismo está a la orden del día.

La diferencia más destacable entre hombres y mujeres terroristas la encontramos en la mayor tendencia de estas últimas al suicidio. No tenemos una explicación clara para este hecho, pues en base a los datos del Banco Mundial las tasas de suicidio para hombres y mujeres son de 13,5 y 7,711, respectivamente, por cada cien mil habitantes. Si bien el número de mujeres que lo intentan es mayor que el de hombres. Además, las tasas de suicidio de mujeres en el mundo árabe son las más bajas: 2,44. En este sentido, las mujeres terroristas, aunque en proporción se suicidan más que los hombres, se pueden considerar como una excepción. En el caso de la mujer suicida es más probable encontrar problemas personales que son hábilmente manipulados por los ideólogos y líderes terroristas que adornan la muerte con contenidos trascendentales y heroicos.

\section{BIBLIOGRAFÍA}

Arendt, H. (2017). Los origenes del totalitarismo. Madrid: Alianza.

Aristóteles. (2012). Ética a Nicómaco. Madrid: Alianza Ed.

Asad, T. (2008). Sobre el Terrorismo suicida. Barcelona: Laertes.

Barrett, P. \& Cheny, S. (2021). FMI Bolg. Obtenido del Blog del Fondo Monetario Internacional: https://blogs.imf.org/2021/02/03/covids-long-shadow-social-repercussions-of-pandemics/?utm_medium=email\&utm_source=govdelivery

Begovic, B. (1 de 3 de 2005). Corrupción: conceptos, tipos, causas y consecuencias. Obtenido de https://www.cadal.org/: https://www.cadal.org/publicaciones/archivo/ documento_26.pdf

Bourdieu, P. (2008). Cuestiones de sociología. Madrid: Akal.

Colom, A. \& Ballester, L. (2020). La epistemología de la complejidad en Ciencias Sociales y de la Educación: debates, modelos de análisis y aplicaciones. En Wendy Morales, Tatiana Valdez, Perspectivas desde la complejidad y Ciencias Sociales (págs. 17-61). Morelos (México): El Colegio de Morelos.

De la Corte, L. (2007). Mitologías del terrorismo, Seminario de Estudios de Seguridad y Defensa USC-CESEDEN, Universidad de Santiago de Compostela, marzo 2007; y las Primeras jornadas sobre el papel de las víctimas de terrorismo en la sociedad española. Universidad Católica de Valencia, abril de 2007. 
De Waal, F. (1993). La politica de los chimpancés. Madrid: Alianza.

Dowse, R. \& Hughes, J. (1982). Sociología política. Madrid: Alianza.

Elias, N. (1990). La sociedad de los individuos. Barcelona: Península.

Fanon, F. (2013). Los condenados de la tierra. Buenos Aires: Fondo de Cultura Económica.

Galtung, J. (1969). Violence, peace, and peace research. Journal of Peace Research, 167-191.

Giddens, A. \& Sutton, P. (2014). Sociología. Madrid: Alianza Editorial.

Godechot, J. (1981). Las revoluciones (1770-1799). Barcelona: Labor.

Gómez, A. et al. (2016). Morir y matar por un grupo o unos valores. Estrategias para evitar, reducir y/o erradicar el comportamiento grupal extremista. Anuario de Psicología Jurídica, 122-129.

González-Calleja, E. (2016). Los estudios sobre terrorismo: balance de los últimos 25 años. Espacio Abierto, 61-76.

Kahneman, D. (2013). Pensar rápido, pensar despacio. Barcelona: Debolsollo (Penguin Randon House).

Keegan, J. (2014). Historia de la guerra. Madrid: Turner Noema.

Laraña, E. (1996) La actualidad de los clásicos y las teorías del comportamiento colectivo. Revista Española de Investigaciones Sociológicas, 74, 15-43.

Lynch, R. et al. (2019). Self sacrifice and kin psycology in war: threats to family predict decisions to volunteer for a women's paramilitary organization. Evolution and Human behavior. Doi:10.1016/j.evolhumbehav.2019.06.001

Martínez, R., \& Lee, M. (2004). Inmigración y delincuencia. Revista de Española de Investigación Criminológica, 1-34.

Pinker, S. (2018). Los ángeles que llevamos dentro. El declive de la violencia y sus implicaciones. Barcelona: Paidós

Reinares et al. (2019). Yihadismo y yihadistas en España. Quince años después del 11M. Madrid: Real Instituto Elcano.

Requena, M. \& Sánchez-Domínguez, M. (2011). Las familias inmigrantes en España. Revista Internacional de Sociología, 81-104.

Rivera, J. (2018). Intereses, organización y acción colectiva. En J. Benedicto, \& M. Morán, Sociedad y política. Temas de sociología política (págs. 269-297). Madrid: Alianza Editorial.

Sandel, M. (2020). La tiranía del mérito ¿Qué ha sido del bien común? Barcelona: Debate.

Trujillo, H. (2004). La conducta humana ante situaciones extremas y críticas. Madrid: Ministerio de Defensa. 
Victor, B. (2004). Las siervas de la muerte. Las mujeres kamikaze en Palestina. Barcelona: Lumen.

\section{FUENTES DE DATOS UTILIZADAS}

Índice de Terrorismo Global (GTD), incidentes terroristas entre 1970 y 2018. Elaborado por el Consorcio Nacional para el Estudio del Terrorismo y las Respuestas al Terrorismo (START).

Banco Mundial. https://datos.bancomundial.org

Informe de Desarrollo Humano 2016 del Programa de las Naciones Unidas para el Desarrollo (PNUD).

Expansión/Datos macro.com. https://datosmacro.expansion.com

Índice de Esclavitud Global 2018. https://www.globalslaveryindex.org

Informe de Fondo para la Paz: Índice de Estado Fallido 2016.

\section{FUENTES BIBLIOGRÁFICAS PARA LA ELABORACIÓN DE UNA BASE DE DATOS DE 667 TERRORISTAS}

Asad, T. (2008). Sobre el terrorismo suicida, Barcelona, Laertes.

Baeza, Á. (1997). Terroristas, Madrid, ABL Press.

De la Corte, L. (2006). La lógica del terrorismo, Madrid, Alianza Editorial.

Fawaz, G. (2007). El viaje del yihadista, Barcelona, Libros de vanguardia.

González-Calleja, E. (2013). El laboratorio del miedo. Una historia general del terrorismo, Barcelona, Crítica.

Juergensmeyer, M. (2001). Terrorismo religioso. El auge global de la violencia religio$s a$, Madrid, Siglo XXI.

Rodicio, Á. (2016). Las novias de la yihad, Madrid, Espasa.

Salas, A. (2010). El palestino, Madrid, Planeta.

Urbano, P. (2003). Jefe Atta. Maestro de suicidas, Barcelona Planeta.

\section{PRENSA: NOTICIAS SOBRE TERRORISMO Y TERRORISTAS}

\section{Nacional}

El Pais. https://elpais.com/

El Mundo. https://www.elmundo.es/ 


\section{Extranjera}

Al Jazeera News (Catar). https://www.aljazeera.com/

Aurora, prensa en español de Israel. https://www.aurora-israel.co.il/

New York Times (EE. UU.). https://www.nytimes.com/es/

CNN News (EE. UU.). https://edition.cnn.com/

BBC News (UK). https://www.bbc.com/news 